

\section{DISCLAIMER}

This report was prepared as an account of work sponsored by an agency of the United States Government. Neither the United States Government nor any agency Thereof, nor any of their employees, makes any warranty, express or implied, or assumes any legal liability or responsibility for the accuracy, completeness, or usefulness of any information, apparatus, product, or process disclosed, or represents that its use would not infringe privately owned rights. Reference herein to any specific commercial product, process, or service by trade name, trademark, manufacturer, or otherwise does not necessarily constitute or imply its endorsement, recommendation, or favoring by the United States Government or any agency thereof. The views and opinions of authors expressed herein do not necessarily state or reflect those of the United States Government or any agency thereof. 


\section{DISCLAIMER}

Portions of this document may be illegible in electronic image products. Images are produced from the best available original document. 


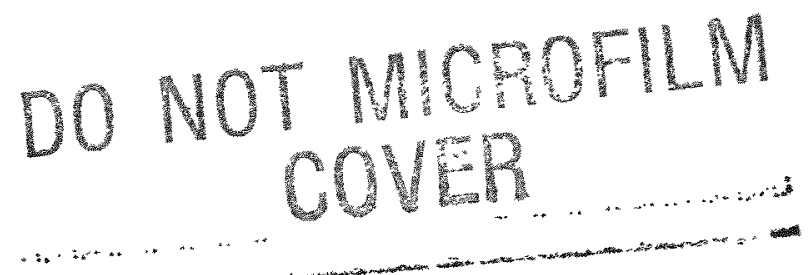

Edited by Dorothy C. Amsden, Group Q-2

Composition and layout by Belinda K. Haag, Group Q-2

Illustrations by Randell Busch and Barbara W. Edwards, Group Q-2

Cover design by Barbara W. Edwards, Group Q-2

This report was prepared as an account of work sponsored by an agency of the United States Goyernment. Nether the United States Government nor any agency thereof, nor any of their employees, makes any warranty, express or mplied, or assumes any legal liability or responsibility for the accuracy, completeness, or usefulness of any information, apparatus, product, or process disclosed, or represents that its use would not infringe privately owned rights. Reference herein to any specific commercial product, process, or service by trade name, trademark, manufacture, or otherwise, does not necessarily constitute or imply its endorsement, recommendation, or favoring by the United States Government or any agency thereof. The views and opinions of authors expressed herein do not necessarily state or reflect those of the United States Government or any agency thereof. 
LSA $-9685-\mathrm{II}$

0883009621

\title{
A History of Critical Experiments at Pajarito Site
}

\author{
H. C. Paxton
}

\section{DISCLAIMER}

This report was prepared as an account of work sponsored by an agency of the United States Government. Neither the United States Government nor any agency thereof, nor any of their employees, makes any warranty, express or implied, or assumes any legal liability or responsibility for the accuracy, completeness, or usefulness of any information, apparatus, product, or process disclosed, or represents that its use would not infringe privately owned rights. Reference herein to any specific commercial product, process, or service by trade name, trademark, manufacturer, or otherwise does not necessarily constitute or imply its endorsement, recommendation, or favoring by the United States Government or any agency thereof. The views and opinions of authors expressed herein do not necessarily state or reflect those of the United States Government or any agency thereof. 


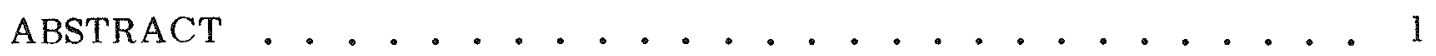

INTRODUCTION ...................... 1

THE FIRST EIGHT YEARS . . . . . . . . . . . . . . 5

Early Weapon Tests .................. 5

Topsy Critical Assemblies . . . . . . . . . . . . . . 8

Elsie Critical Assemblies .. . . . . . . . . . . . 10

Little Eva . . . . . . . . . . . . . . . . . . 10

Lady Godiva . . . . . . . . . . . . . . . . 11

Critical Heavy-Water Enriched Uranium Solutions . . . . . . 13

Jemima Critical Assemblies . . . . . . . . . . . 15

Jezebel ................... 16

Hydro and Exponential Columns. . . . . . . . . . . 18

Miscellaneous Assemblies . . . . . . . . . . . . 19

THE ROVER PERIOD ................... 20

Graphite-Moderated Propulsion Reactors. . . . . . . . . 20

Dumbo Reactors . . . . . . . . . . . . . 27

Cavity Reactors .................... 28

Temporary Assemblies. . . . . . . . . . . . . . 30

Flattop ...................... . . 31

Godiva IV . . . . . . . . . . . . . . . 32

Big Ten .................... 33

SINCE 1972 . . . . . . . . . . . . . . . 35

NASA-Sponsored Activities . . . . . . . . . . 36

Parka ........................ 37

Kinglet . . . . . . . . . . . . . . 37

Sheba ...................... 38

Skua ....................... 40

CONTINUING CAPABILITY .................. 41

ACKNOWLEDGMENTS . . . . . . . . . . . . . 43

REFERENCES ...................... 4 43 


\title{
A HISTORY OF CRITICAL EXPERIMENTS AT PAJARITO SITE
}

by

H. C. Paxton

\begin{abstract}
This account describes critical and subcritical assemblies operated remotely at the Pajarito Canyon Site at the Los Alamos National Laboratory. Earliest assemblies, directed exclusively toward the nuclear weapons program, were for safety tests. Other weapon-related assemblies provided neutronic information to check detailed weapon calculations. Topsy, the first of these critical assemblies, was followed by Lady Godiva, Jezebel, Flattop, and ultimately Big Ten. As reactor programs came to Los Alamos, design studies and mockups were tested at Pajarito Site. For example, nearly all 16 Rover reactors intended for Nevada tests were preceded by zero-power mockups and proof tests at Pajarito Site. Expanded interest and capability led to fast-pulse assemblies, culminating in Godiva IV and Skua, and to the Kinglet and Sheba solution assemblies.
\end{abstract}

\section{INTRODUCTION}

This is a history of the remotely operated assemblies, past and present, critical and subcritical, at Pajarito ${ }^{*}$ Site, which is located in a canyon at the Los Alamos National Laboratory (Fig. 1). In 1946, before remote operation, Pajarito Canyon was chosen as the site for critical assemblies work because its isolation would protect others from radiation if a criticality accident should occur. The first eritical assemblies were manipulated by hand, a dangerous procedure that led to Louis Slotin's death in 1946 when a component of the assembly slipped into a more reactive position, producing a superprompt-critical pulse of radiation.

\footnotetext{
*Pronounced pä-hä-rē-tō; Spanish for little bird.
} 


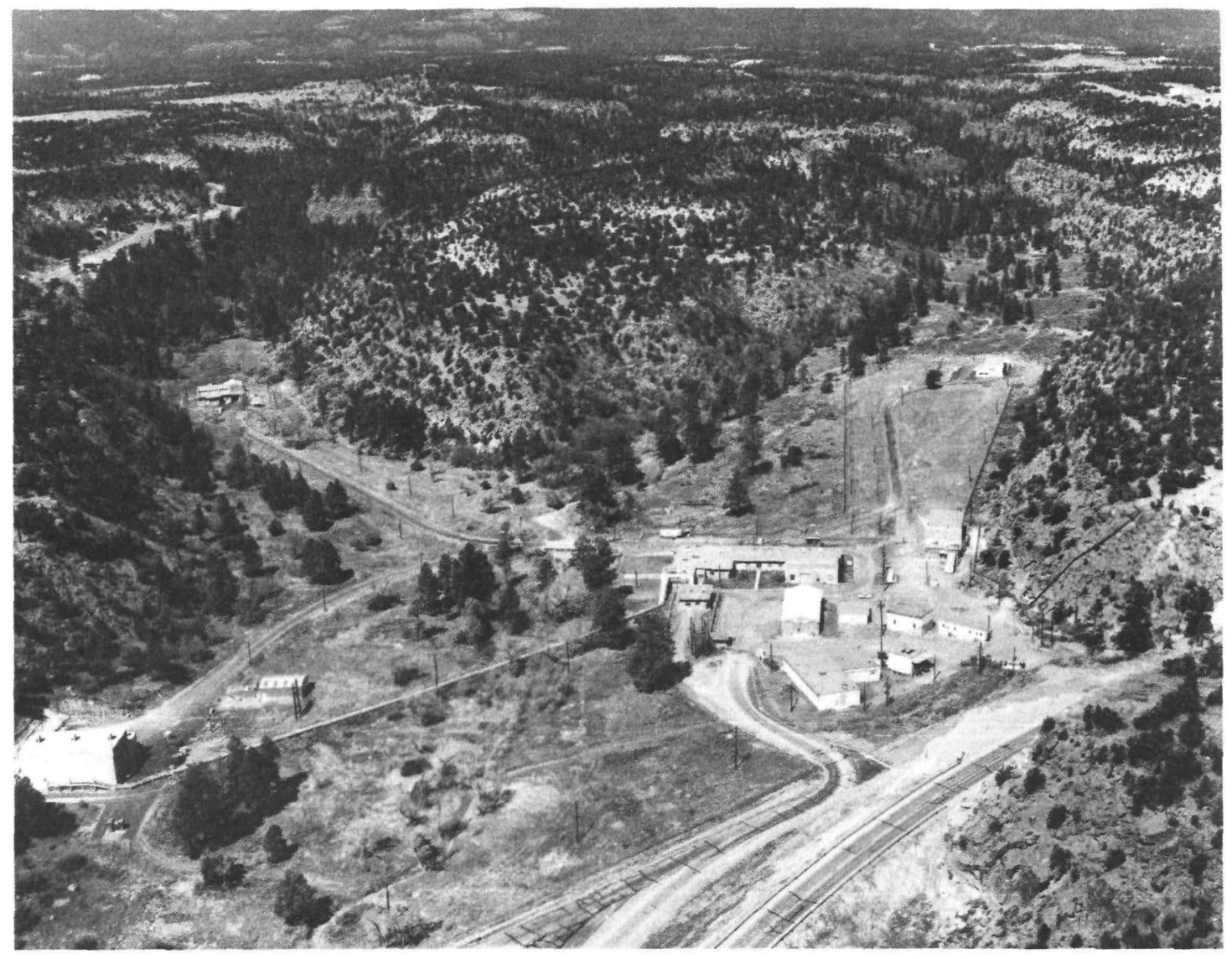

Fig. 1.

Pajarito Site from the air, as it appeared in 1969. Kiva 1 is at the right rear. The permanent laboratory with control rooms (right center) and Kiva 2 (left rear) were occupied in 1953. Kiva 3 (left foreground) became operable in 1960 to accommodate the Rover Program.

After the fatal accident, direct manipulation of fissile materials that could lead to a planned or accidental critical (self-sustaining or runaway) nuclear configuration was banned. At the same time, it was recognized that criticality experiments were necessary to the continuation of the overall weapons program. The guidelines adopted by the Laboratory, therefore, emphasized personnel safety as a first priority, with the safeguarding of the fissile material as well as versatility and reproducibility of experiments as important objectives. No experiment was to be conducted without a detailed set of operating procedures that had been reviewed and approved by Laboratory management.

A variety of options were available within the guidelines. For example, a very early choice had to be made between hot-cell type of manipulation and true remote control that used large (quarter-mile) separation rather than heavy walls for protection of the operators. Similarly, a choice had to be made between complex robots duplicating human dexterity and adaptability, and more conventional machines limited to much simpler motions. In either case, the ability to reverse operations and provide fail-safe assembly procedures was a requirement. After much consideration, it was decided 
that remote operations and conventional machines should be used and that gravity provided the most reliable fail-safe mechanism.

Operating procedures for each class of experiment were prepared and reviewed in detail before the experiment was approved. One individual was designated to monitor the safety of the experiment, but any member of the crew could stop the experiment when safety was in question.

The effectiveness of this design and operating philosophy can be judged by the fact that critical assembly operations have caused no fatality or disabling injury due to nuclear radiation in the 35 years since they began.

Originally, the remote-control Critical Experiments Facility consisted of a critical-assembly laboratory known as Kiva," located one-quarter mile from a control room in an existing shack (Fig. 2). An exclusion area provided radiation protection by keeping people beyond this distance whenever the remotely controlled critical assemblies were operated. Two additional kivas were eventually built to accommodate burgeoning experiments (Fig. 3).

Kiva operations began in April 1947 as subcritical measurements for weapon safety guidance. Accidental criticality had to be avoided during the handling, storage, and transportation of weapon components, and during the assembly and manipulation of weapons. The experimental guidance was

\footnotetext{
*The Hopi Indian name for a round ceremonial chamber.
}

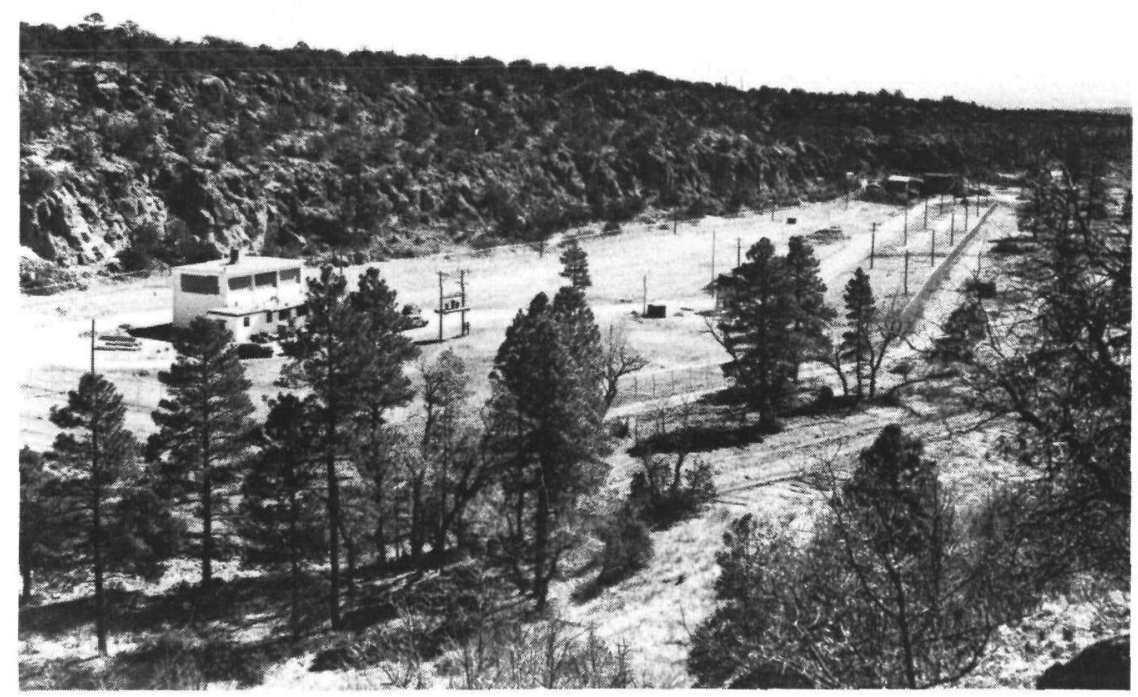

Fig. 2.

The original Kiva (now called Kiva 1), as the remote critical assembly laboratory was called. The original control room and general laboratory were in a shack one-quarter mile distant, seen in the background. 


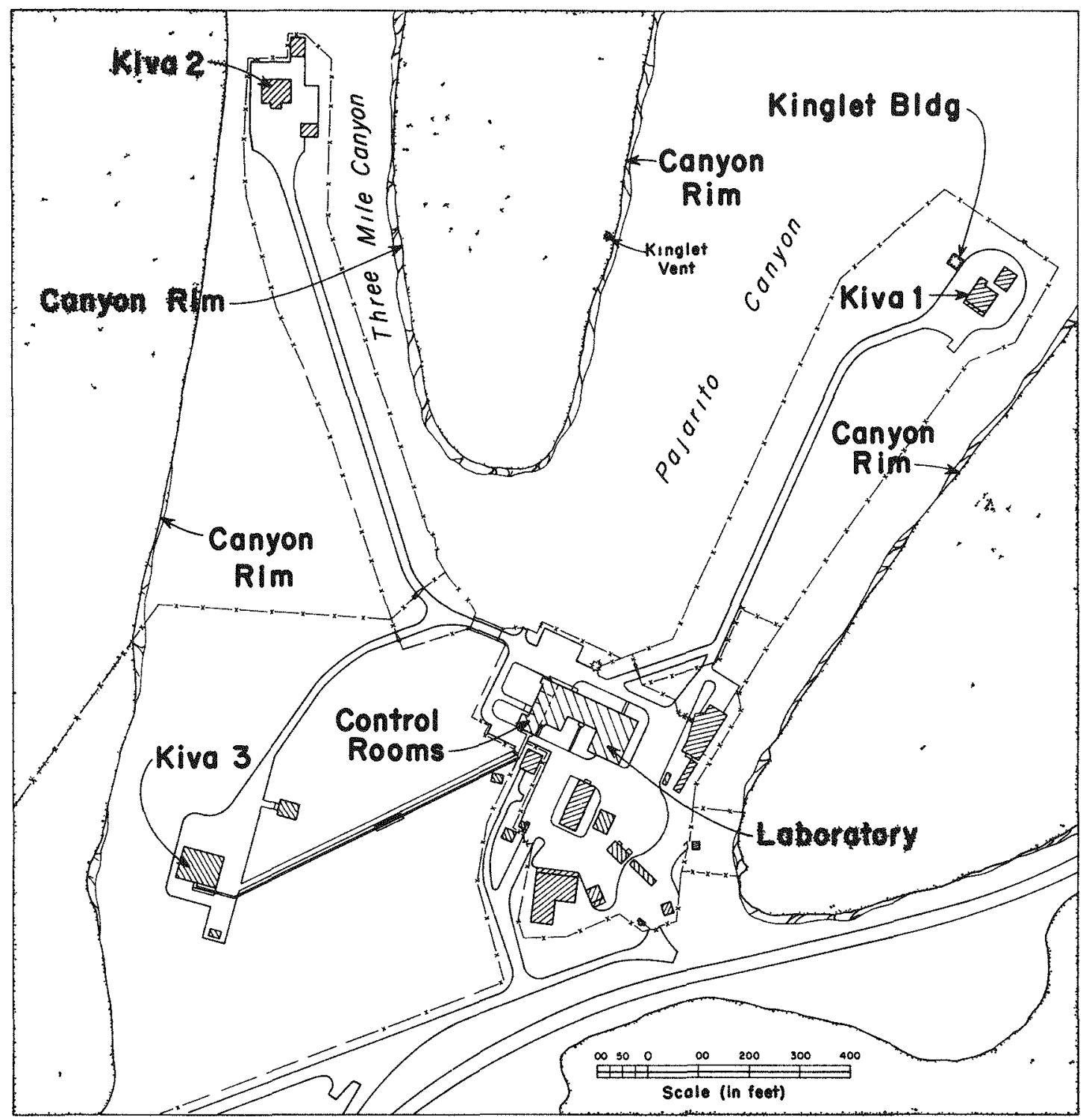

F1g. 3.

Present Pajarito Site layout and terrain.

necessary to avoid impractical restrictions. These tests established safe, subc ritical limits for the fissile content of weapon capsules.

In early brute-force weapons, yield was limited by criticality-safety restrictions, and each high-yield capsule was tested to be certain that those restrictions were satisfied. As weapon design became more subtle, the need for capsule tests decreased, but guidance for the storage of complete weapons became more important, especially for shipboard storage in severely limited space.

In addition to safety tests, neutronic experiments were conducted to obtain information for checking detailed weapon calculations made possible 
by the development of high-speed computers. The first critical assembly for this purpose was the Topsy enriched uranium core reflected by natural uranium. Supplementing Topsy were three other critical assemblies: Lady Godiva, a sphere of unreflected enriched uranium, and eventually Jezebel and Flattop to round out information about the fissile isotopes $235 \mathrm{U},{ }^{23}{ }^{\mathrm{U}}$, and ${ }^{239} \mathrm{Pu}$ in both bare and uranium-reflected assemblies.

When reactor research began at Los Alamos, critical design studies or mockups were sought. The major demand for criticality experiments came from the Rover Nuclear Propulsion Program. During the 17 years of Rover's existence, parametric studies were conducted at Pajarito Site to help designers, followed by zero-power mockups and checkouts of nearly all 16 Rover reactors that were intended for high-temperature operation at the Nevada Nuclear Rocket Development Site.

Expanded interest and capability led to fast-pulse assemblies culminating in Godiva IV and Skua. They also led to Big Ten with its $10 \%$ enriched uranium core reflected by natural uranium, the Kinglet circulating highly enriched uranium solution assembly, and the Sheba unreflected assembly of $5 \%$ enriched uranium solution.

\section{THE EIRST EIGHT YEARS}

From 1947 to 1955 the weapons program received primary emphasis. Safety tests made use of the Bomb Mockup, Topsy, and Elsie machines before critical operation, and the Comet and Planet machines when Topsy and Elsie were committed to critical assemblies. Although neutronic studies of Topsy critical assemblies, and the succeeding Godiva and Jezebel assemblies, were directed toward weapon physics measurements, results also applied to fast reactors. Elsie critical assemblies, on the other hand, applied specifically to gun-type weapons and other experimental devices. Ultimately, a few assemblies were designed solely to provide information for reactor designers.

\section{Early Weapon Tests}

The first remotely controlled assembly machine, the Bomb Mockup (Fig. 4), was sized similarly to Fat Man, the Nagasaki weapon. The Bomb Mockup was split at the equator and the upper hemisphere was raised for access to a central region that could accommodate a variety of fissionable components. For operation, the assembly was closed remotely. It would separate automatically (this is what we call a scram) if criticality should be approached more closely than intended. All tests with the Bomb Mockup were subcritical neutron-multiplication measurements in which the response of neutron counters relates to the margin below criticality. An excessive counting rate would initiate a scram.

The Bomb Mockup tests had several purposes: to demonstrate the safety of implosion-weapon components, confirm the intended reactivity of production cores, and provide guidance for new implosion-weapon design. These tests were supplemented by manual, low-multiplication measurements in the cruder, original Slotin bomb mockup that had no remote-control features unless mounted on an assembly machine. Further safety tests showed effects 


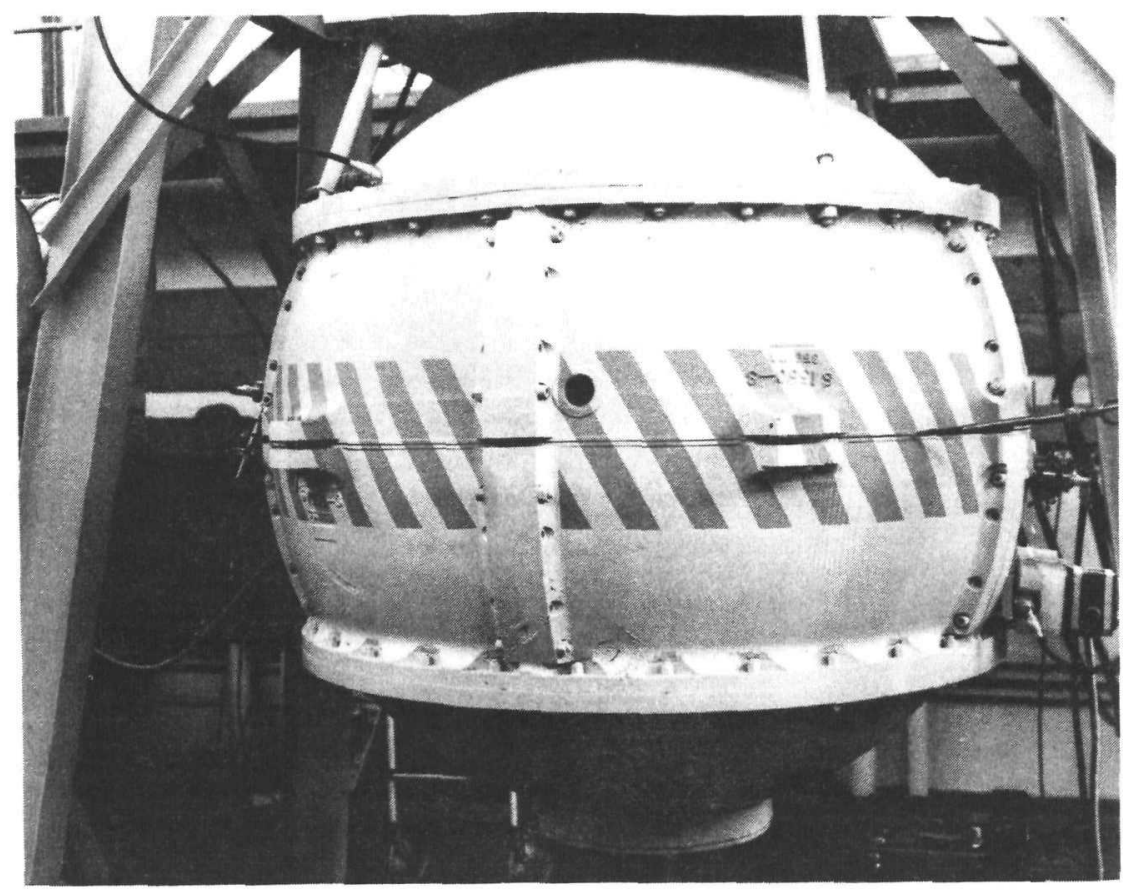

Fig. 4.

The Bomb Mockup, simulating the first implosion weapon, but with replaceable capsules. Measurements in this assembly established subcritical conditions for more advanced designs than the Nagasaki weapon.

of immersing weapon components in water. For this purpose, a tank set up temporarily was filled remotely and a large dump valve served as a scram mechanism.

Another temporary setup in 1947 was a conerete vault of adjustable size (Fig. 5) that could be closed remotely and opened as an automatic scram. Cubic arrays of weapon cores and capsules were set up in the vault. Multiplication measurements of these arrays provided guidelines for safe storage of weapon components. 1

Further safety tests of weapon cores and capsules in paraffin, concrete, and natural uranium metal made use of a universal assembly machine, Topsy (Fig. 6), that was intended ultimately for critical assemblies. ${ }^{2}$ Typically, a remotely activated hydraulic lift raised a core into a large block of paraffin, concrete, uranium, or the Slotin mockup, ${ }^{*}$ which was supported by a heavyduty platform. As in all suberitical measurements, multiplication was detected by neutron counters.

In the fall of 1948, Topsy was no longer available for subcritical tests, as it was devoted entirely to critical assemblies. To take its place for subcritical testing, another machine intended for critical assemblies, Elsie,

\footnotetext{
*The mockup designed by Louis Slotin, unlike the succeeding Bomb Mockup, was not a self-contained machine; instead it had to be mounted on a remotely operated device such as the Topsy mechanism.
} 


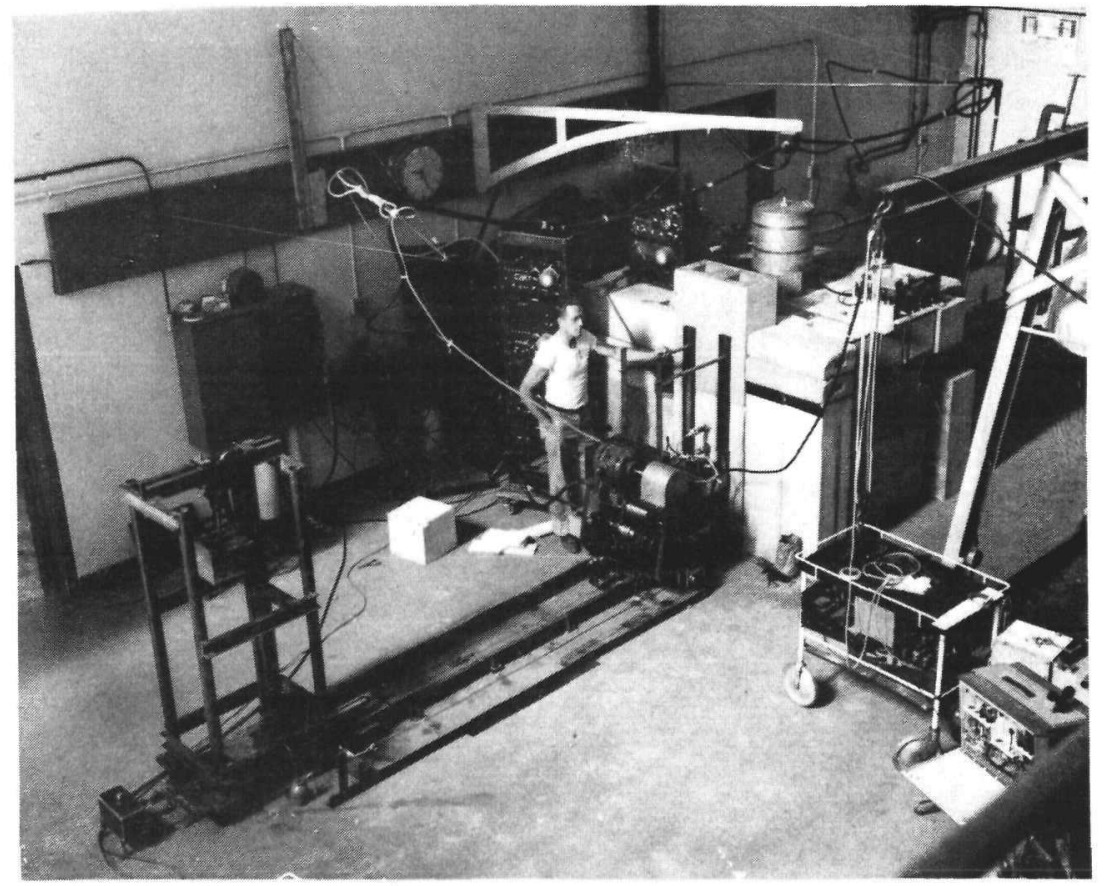

Fig. 5.

A concrete vault with remote closure for early weapon-capsule storage tests. The entire stockpile was called upon for these tests. Stringent security was maintained, including machine-gun emplacements and a requirement that all personnel wear distinctive jackets while moving between buildings. The participant is Raemer Schreiber.

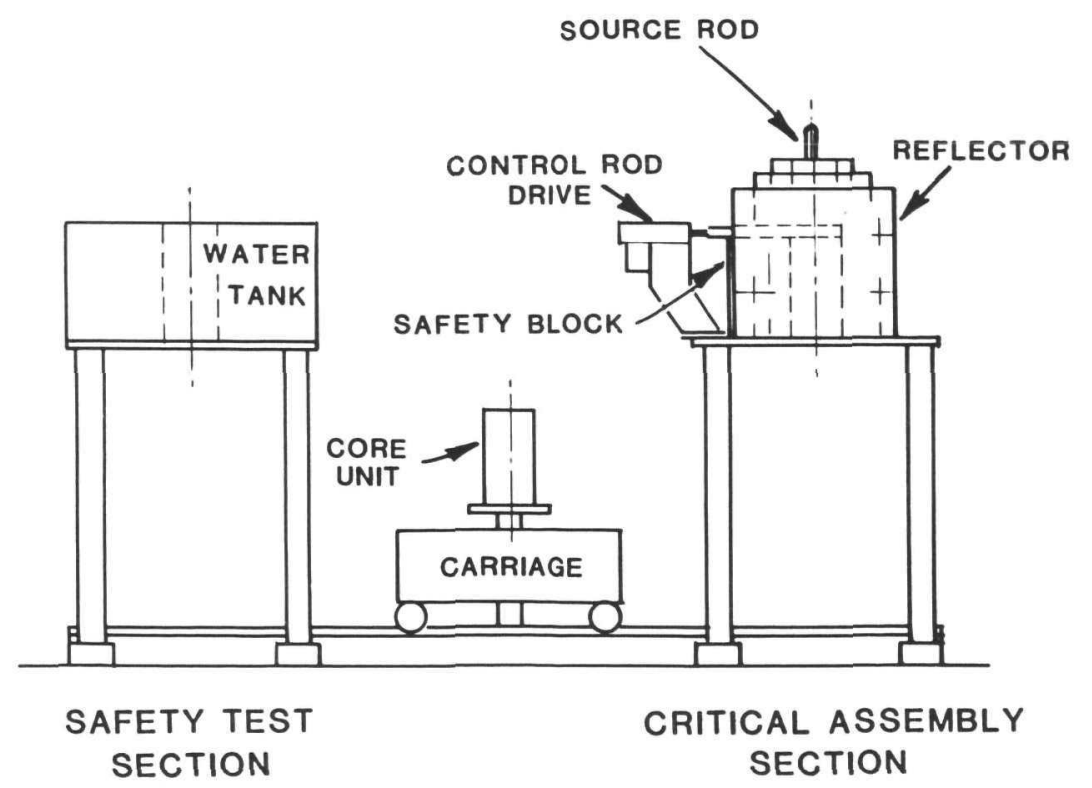

Fig. 6.

The original Topsy assembly machine. The carriage was moved to the water tank (for safety test) or reflector section before the core unit was raised into position. The water tank was removed after critical conditions were established. 
was diverted temporarily. Elsie was followed by a simpler vertical lift machine called Comet (so named because of its designer Jano Haley). Comet proved so popular, even for critical assemblies (discussed later), that it was supplemented by a twin called Planet.

Planet and Comet carried the burden of safety tests for gun-type weapons and their components. They were also used to provide data for designing new cylindrical experiments. Safety and design tests using Planet or Comet continue to the present time.

\section{Topsy Critical Assemblies}

Eighteen months after Kiva became operational, the Topsy assembly 2 (she just growed) reached criticality. The real significance of the Topsy operation was that this metal assembly of enriched uranium in thick natural uranium provided the first basic information about fast-neutron fission chains in a readily computable system. Superprompt-critical pulses that had occurred were too fleeting for neutronic experiments, and earlier critical mockups of a mercury-cooled fast reactor at another Laboratory site were too complex for reliable calculation. Thus, Topsy was the first of a series of assemblies to provide fast-neutron data for checking the powerful computational techniques that relied upon high-speed machines being developed at the time.

These techniques, used for both weapon and fast-reactor design, required experimental confirmation because of uncertainties in the many input cross sections. In addition to observed critical specifications, data for this purpose included descriptions of neutron energy spectra, effective cross sections of various materials within the assembly, the time behavior of prompt-neutron chains (on a scale of microseconds), and delayed-neutron characteristics (on a scale of seconds). Prompt neutrons from fission lead to the runaway reaction in a nuclear explosion; the minute fraction of delayed neutrons makes reactor control possible.

These neutronic measurements to assist weapon designers increased in importance as designs became sophisticated. They gradually supplanted direct tests on components and assembled weapons, but even today such tests have not been eliminated.

The principal Topsy assembly consisted of a $U(94)^{*}$ core in a thick natural uranium reflector (Fig. 7). The pseudospherical core, with half-inch steps on the surface, was raised into a cavity within a reflector that was pseudospherical on a larger scale. Control bars of natural uranium entered cavities within the reflector. The original assembly with integral core was modified such that the upper portion of the core, mounted on a U(94) plate, remained within the main body of the reflector. A radial hole (called a glory hole), one-half-inch in diameter through the reflector and U(94) plate, with appropriate fillers, provided access for internal measurements.

\footnotetext{
${ }^{*}$ Uranium enriched to 94 wt\% $235 \mathrm{U}$.
} 


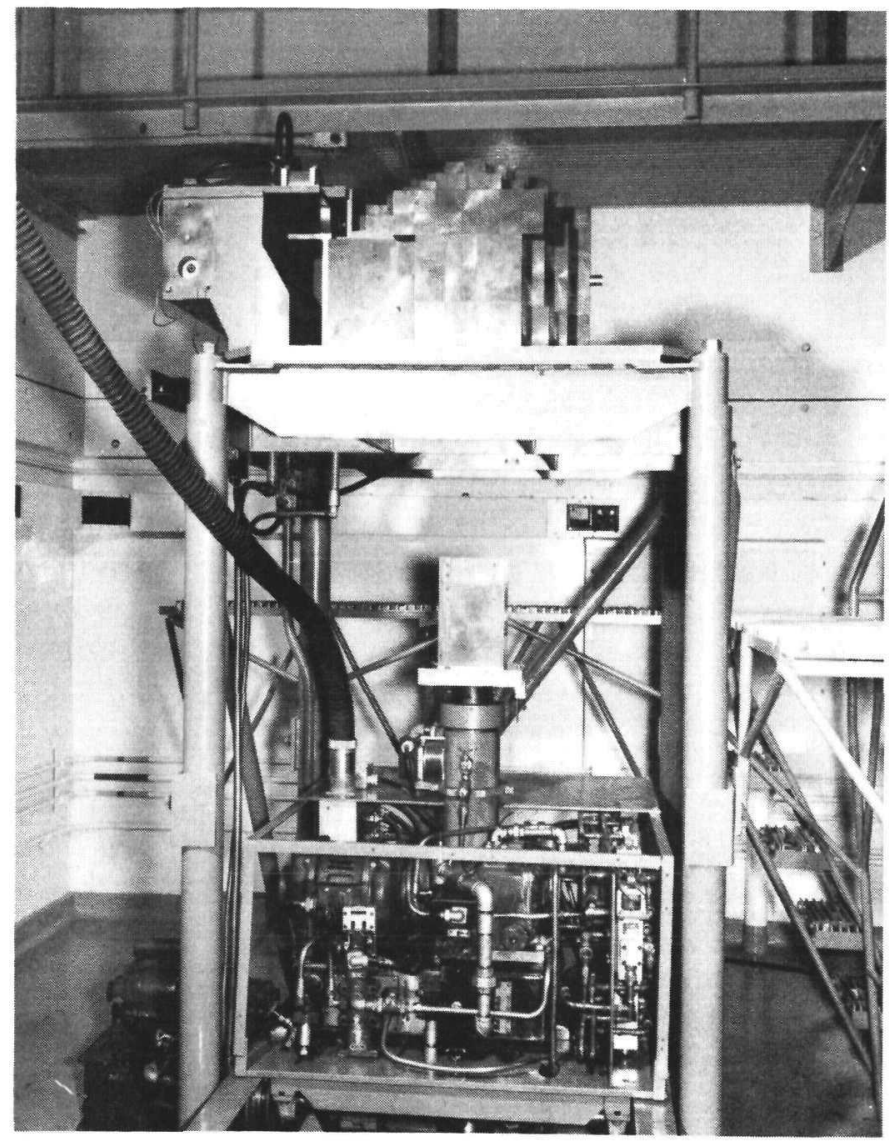

Fig. 7.

The first Topsy critical assembly. An enriched uranium core embedded in part of the natural uranium reflector was raised into a cavity in the main reflector body. Spherical or cylindrical cores were approximated by half-inch-cubic blocks.

Inserted into the glory hole for various measurements were foils for neutron activation, fission chambers for Rossi- $\alpha$ and fission rates, and samples of materials for reactivity contributions. ${ }^{3}$ Such measurements became standard for most critical assemblies. Of particular value are the following five classes of data.

- Neutron distributions throughout the assembly, generally fission rates of $235 \mathrm{U}$ or $239 \mathrm{Pu}, 237 \mathrm{~Np}$, and $238 \mathrm{U}$, but sometimes activation response of detectors such as sulfur (for high energy) and gold (for low energy). 4

- Spectral indexes, consisting of ratios of fission rates of isotopes with appreciably different responses to neutron energy, typically $\bar{\sigma}_{f}(235 \mathrm{U}) /$ $\bar{\sigma}_{\mathrm{f}}(238 \mathrm{U})$ or $\bar{\sigma}_{\mathrm{f}}(239 \mathrm{Pu}) / \bar{\sigma}_{\mathrm{f}}(238 \mathrm{U})$, and $\bar{\sigma}_{\mathrm{f}}(237 \mathrm{~Np}) / \bar{\sigma}_{\mathrm{f}}(238 \mathrm{U})$, often with small quadruple fission chambers.

- Rossi- $\alpha$ at delayed criticality and its variation with reactivity in the neighborhood of criticality. 5 
- Positive periods at reactivities somewhat above delayed criticality normally limited to periods greater than 10 seconds.

- Central reactivity coefficients of many materials, including fissionable, absorbing, and structural materials, and maps of their reactivity contributions throughout the assembly. 6

Other modifications of Topsy consisted of a reflector at an average thickness of 11 inches instead of the normal 9 inches and cores of parallelepiped shape. Other cores had average density or concentration reduced to as much as $50 \%$ of normal by means of distributed half-inch cubic voids or blocks of natural uranium. ${ }^{7}$ Uranium-hydride cores were simulated first by polyethylene cubes distributed throughout the metal core, 8 and later as compacts of $\mathrm{UH}_{3}$ powder, uranium powder, and polyethylene with mean composition $\mathrm{UH}_{3} \mathrm{C}_{.}{ }^{3}$ With both hydride and metal cores, a nickel reflector was substituted for that of uranium. Finally, a spherical plutonium core, with mass adjustment buttons on the surface, was introduced into the uranium reflector. 10

After 7 years of critical operation, the Topsy assembly machine was retired. For practical purposes, it was replaced by the more stable Flattop machine (discussed later).

\section{Elsie Critical Assemblies}

Critical assemblies mounted on the Elsie machine (called Elsie assemblies) were intended to provide data to aid in the design of gun-type devices less massive than Little Boy, the Hiroshima weapon. The core was a split U(93) cylinder with the upper portion secured in a vertical reflector cylinder with cap. The reflector consisted of various combinations of materials that would be appropriate for weapons. Horizontal control rods entered the reflector cap immediately above the upper core portion. In each case, the $\mathrm{U}(93)$ mass was adjusted to attain criticality with the two parts of the core in contact.

The Elsie critical experiments, which were conducted in 1950, included the standard survey in abbreviated form. A vertical glory hole extending through the reflector cap and into the core made internal measurements possible.

\section{Little Eva}

Little Eva, a Topsy-like enriched uranium metal assembly with a thinner natural uranium reflector, was the next critical assembly. It was improvised for demonstrating neutron-distribution measurement by means of photographic emulsions. A drill-press frame was adapted as a mount for the assembly. No attempt was made to complete a standard survey of Little Eva's characteristics. The photographic emulsion technique, however, was demonstrated successfully. 11 In 1958, Little Eva was moved to the Nuclear Rocket Development Site at Nevada where it was used to calibrate foils for reactor diagnostics. 
With Topsy still in operation, a second critical assembly for basic studies, Lady Godiva (she was unclad, like the lady), began operation in 1951. This essentially bare sphere of enriched uranium, simpler than the two-component Topsy, had not been planned earlier because of undetermined sensitivity to outside influence-facetiously, even the effect of a fly alighting on the surface. The critical size was established earlier by means of a near-critical pseudosphere set up on the Comet machine. 12 The Lady Godiva sphere, on the Elsie machine, was subdivided into a stationary central section with retractable upper and lower caps (Fig. 8). The central section contained a diametral glory hole with fillers, and channels for two highly enriched uranium control rods. Compensation for openings in the glory hole was provided by mass-adjustment buttons of enriched uranium that fit into recesses in the spherical caps. Lightweight component mounts resulted in small extraneous reflection. 13

By late 1962, the usual critical characteristics of Lady Godiva had been thoroughly established. $3,4,6$ Calibration of control rods and mass-adjustment buttons, and the reactivity equivalence of enriched uranium as a function of

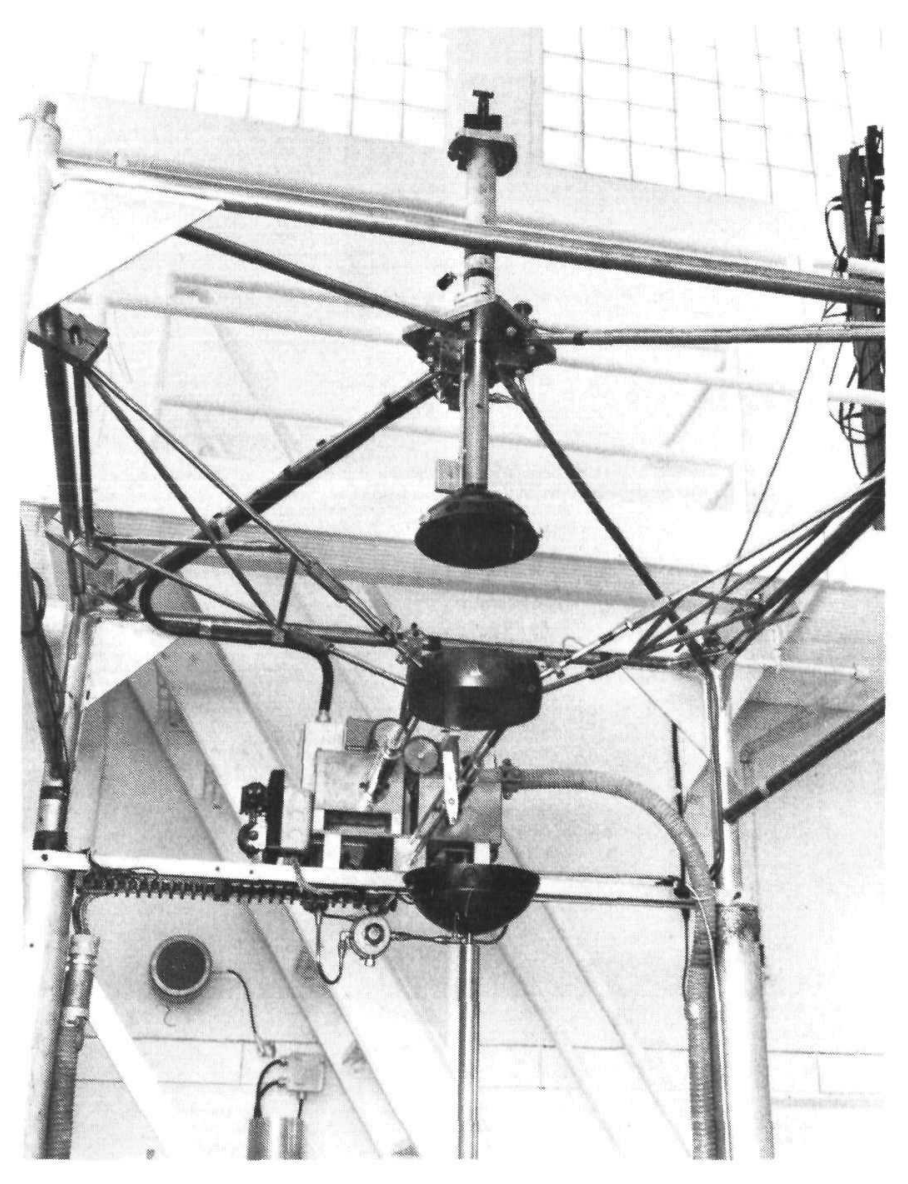

Fig. 8.

The Lady Godiva critical assembly of highly enriched uranium. For operation, the upper cap is dropped and the lower cap is raised to form a near-sphere without reflector. 
radius provided the means of correction to an idealized sphere (i.e., without surface irregularities or nonuniformities). Other features of the standard survey were extensive. In addition, however, positive periods were measured throughout $97 \%$ of the interval between delayed and prompt criticality. Because extrapolation was predictable, plans to investigate the behavior of Lady Godiva in the neighborhood of prompt criticality were then formulated.

Here, the account of Lady Godiva must be interrupted to introduce the second kiva, a result of the original kiva becoming overloaded to the extent of frequent three-shift operation. Kiva 2 was occupied at the beginning of 1953. After Lady Godiva was moved to the second kiva, its operation was extended gingerly into the prompt-critical region with the result that superprompt-critical radiation pulses (Fig. 9) were being produced by mid-1953.14 These sharp, intense pulses were terminated by thermal expansion of the assembly. At one stage, Lady Godiva was moved outdoors and elevated well above the ground (Fig. 10) to eliminate the effect on pulse shape of room-return neutrons. The resulting shapes agreed with calculation.

Although intended initially to confirm predicted superprompt-critical behavior, 15 the sharp, intense pulses were immediately in demand as sources for biological studies (Fig. 11), solid-state experiments, and proof tests of instrumentation and controls that were supposed to withstand radiation from a nuclear explosion. ${ }^{16}$ The result was that Lady Godiva became a radiation
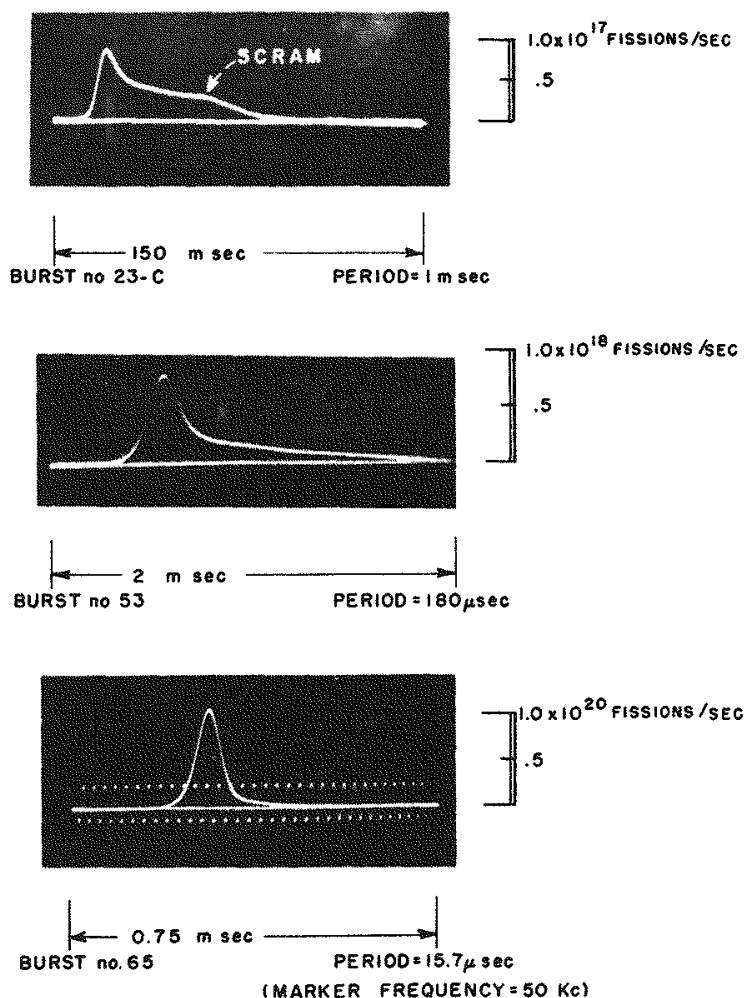

Fig. 9.

Superprompt-critical responses of Lady Godiva. As excess reactivity increases, the neutron-time relation progresses toward a fully developed pulse. 


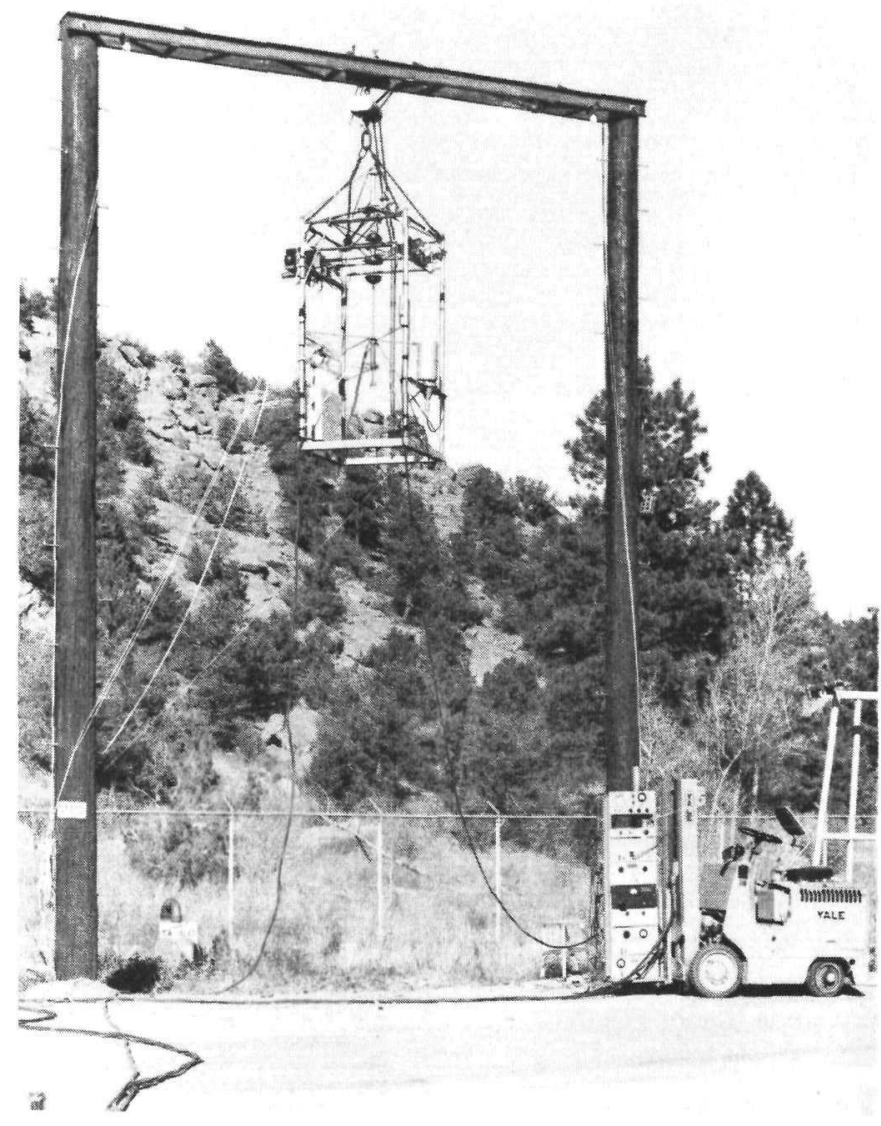

Fig. 10.

Lady Godiva suspended outdoors to eliminate the effect of room-return neutrons.

source and produced a total of about 1000 of the prompt-radiation bursts-but not without incident. Twice the delicate limit beyond prompt criticality that could be tolerated was exceeded.17 The first, which occurred in February 1954, warped uranium parts slightly but not sufficiently to prevent further operation. The second, 3 years later, was more extreme. It produced severe warping and oxidation of parts and damaged the lightweight supports (Fig. 12). As a result, Lady Godiva was retired and replaced by Godiva II, a sturdier bare $U(93)$ assembly designed specifically for prompt-burst production. 18

In some cases, the pulses from Lady Godiva provided an alternative to expensive field tests. Thus, Lady Godiva ultimately led to the family of fast-burst reactors that extended to Sandia National Laboratories, Oak Ridge National Laboratory, Lawrence Livermore National Laboratory, White Sands Missile Range, and Aberdeen Proving Ground.

\section{Critical Heavy-Water Enriched Uranium Solutions}

In 1952, two sets of critical experiments with heavy-water solutions of enriched uranium as uranyl fluoride ${ }^{19}$ provided information supporting an 


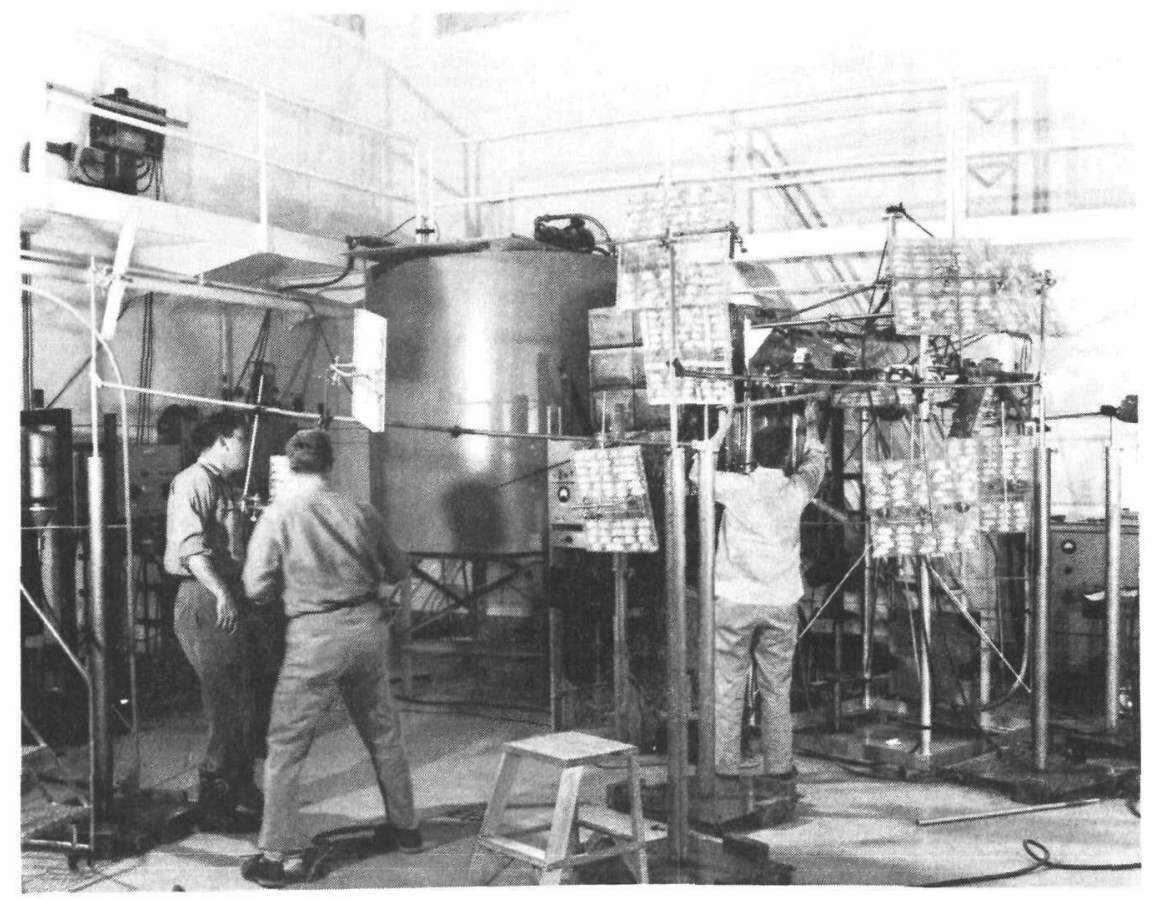

Fig. 11.

Mice disposed about Lady Godiva for prompt-burst irradiation. Effects on other irradiated mammals, including burros and monkeys, when extrapolated to humans, helped to establish both lethal doses and greater immediately incapacitating doses. Dr. Payne Harris is on the far left.

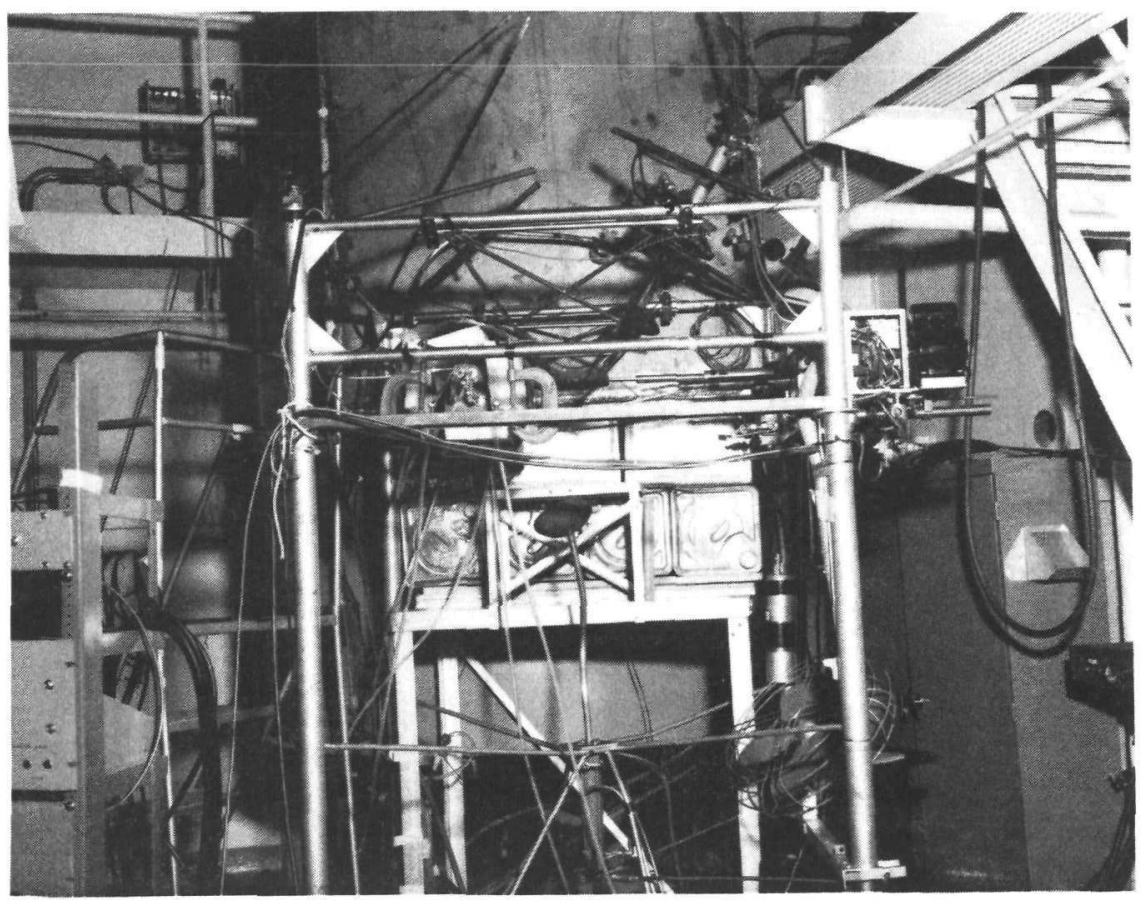

Fig. 12.

Lady Godiva after the accident that led to its retirement. The damaging pulse was $1.2 \times 10^{17}$ fissions. 
idea of Edward Teller about thermonuclear weapons. By the time the experiments were completed, Teller had lost interest; thus, the results became more appropriate for reactor application than for weapon design. In one set of experiments, the solution was in 25- and 30-inch-diameter tanks without a surrounding reflector. Solution heights were adjusted to criticality with $\mathrm{D}_{2} \mathrm{O}$ solutions at $\mathrm{D} / 235 \mathrm{U}$ atomic ratios of 230 and 419 in the smaller tank and 856 and 2081 in the larger tank. An axial glory hole provided for internal measurements with resonance detectors and fission chambers.

In the other set of experiments, solution spheres were centered in a 35 -inch-diameter spherical container into which $\mathrm{D}_{2} \mathrm{O}$ was pumped from a reservoir at the base. Criticality was attained in six solution spheres from 13.5 - to 18.5 -inch diameter at $\mathrm{D} / 235 \mathrm{U}$ atomic ratios from 34 to 431 . For this series, a sheath for detectors entered the solution through a vertical filling tube. On completion of the heavy-water experiments, the equipment was retired.

\section{Jemima Critical Assemblies}

The Jemima critical experiments were proposed to guide the use of intermediately enriched uranium in various laboratory programs. Actually, the results were most useful for general criticality safety guidance. For this series of experiments, conducted in 1952, Comet was fitted with lightweight supports for 10.5 -inch-diameter critical cylinders of uranium 20 at average $235 \mathrm{U}$ enrichments of 37.7 and $53.6 \%$. These average values were attained by interleaving plates of $\mathrm{U}(93.4)$ and plates of natural uranium. An assembly averaging $29.0 \% 235 \mathrm{U}$ required blocks of enriched and natural uranium outside the plates for criticality. Reactivity control was by means of an external uranium plate that moved parallel to the axis of the assembly.

Two years later, this Jemima series was supplemented by a critical assembly 21 in Kiva 2 with a core averaging $16.25 \% 235 \mathrm{U}$. The 15 -inchdiameter core also consisted of interleaved plates of enriched and natural uranium. It was enclosed in a 3-inch-thick reflector of natural uranium.

In all cases, there were measurements of Rossi- $\alpha$ and neutron distributions. Spectral indexes were averaged to smooth out variations due to structure.

As a preliminary to the Jemima assemblies, an undiluted assembly of the enriched uranium plates was intended. But an error in the approach to criticality led to a superprompt-critical excursion without damage. A subsequent analysis indicated that the excursion had been terminated by thermal expansion, confirming the expected behavior of solid metal assemblies. 22 This bolstered the plan for prompt-critical experiments with Lady Godiva.

An earlier accidental excursion (superprompt-critical pulse) had occurred in a tank for measuring the multiplication of submerged weapon components. 23 After measurements indicative of the critical separation distance between two components, the system was to be scrammed (as a flourish) by rapid withdrawal of one component. On the way out, however, it swung close to the other component, leading to the excursion. The parts were slightly oxidized. 
In addition to these accidents and the two with Lady Godiva, there have been four others at Pajarito Site in which prompt criticality presumably was attained. In none of these four was there damage. 17,24

\section{$\underline{\text { Jezebel }}$}

In 1954, Jezebel (Figs. 13 and 14) was set up in Kiva 2 as an unreflected spherical critical assembly of delta-phase plutonium. 10 This assembly was to satisfy the need for neutronic information about plutonium that would parallel the information about enriched uranium provided by Lady Godiva. For Jezebel, a central section floated on taut wires that also steered upper and lower caps. The result was little extraneous reflection. Components of the sphere, upper and lower caps and two parts held together as the central section, were plated with nickel for health protection. The assembly, mounted on a light, tubular frame, was portable. The normal Jezebel, with parts consisting of plutonium containing $4.5 \% \quad 240 \mathrm{Pu}$, was surveyed thoroughly by the standard techniques. ${ }^{3,6}$ Positive periods, however, were extended to 4 seconds instead of observing the usual 10-second limit.

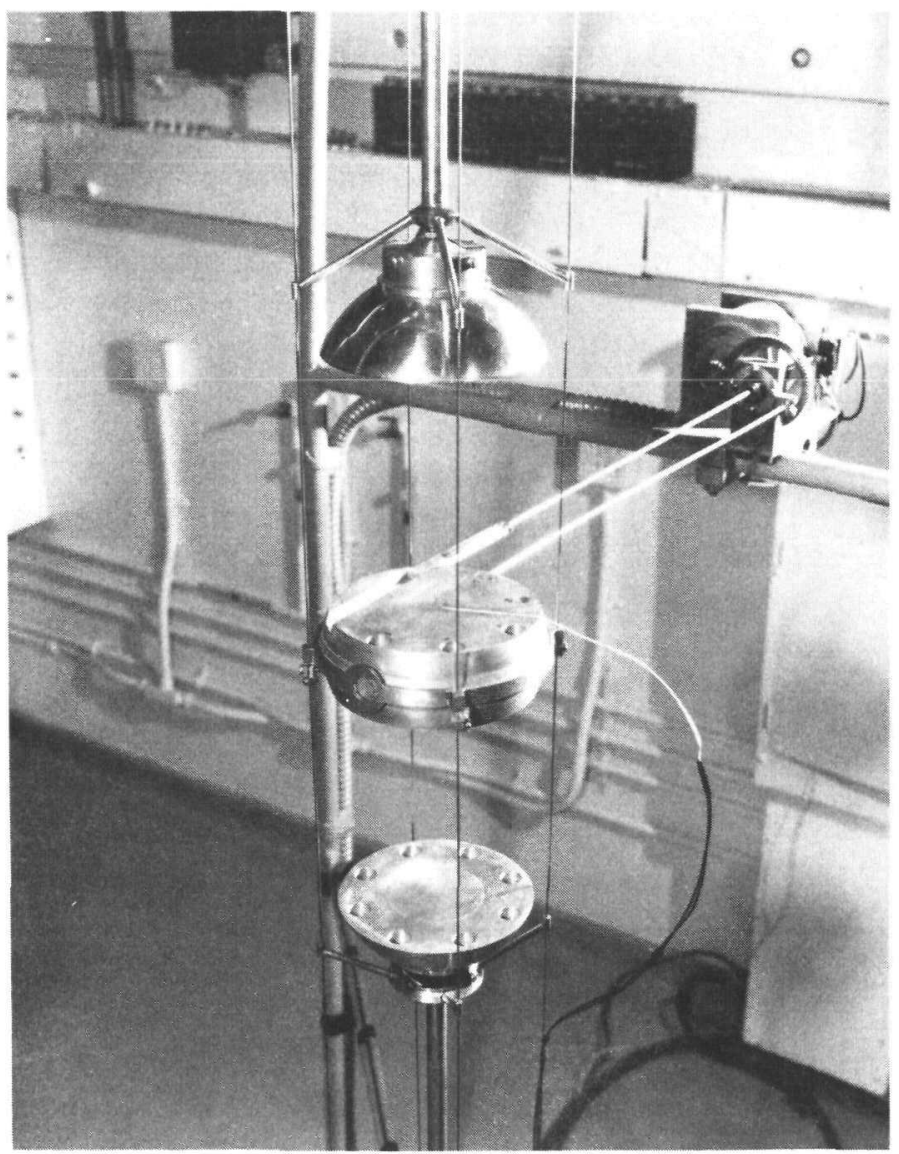

Fig. 13.

The Jezebel unreflected plutonium assembly. Upper and lower caps are withdrawn whenever Jezebel is not in operation. Both caps are guided by taut wires that provide alignment while adding little to incidental reflection. 


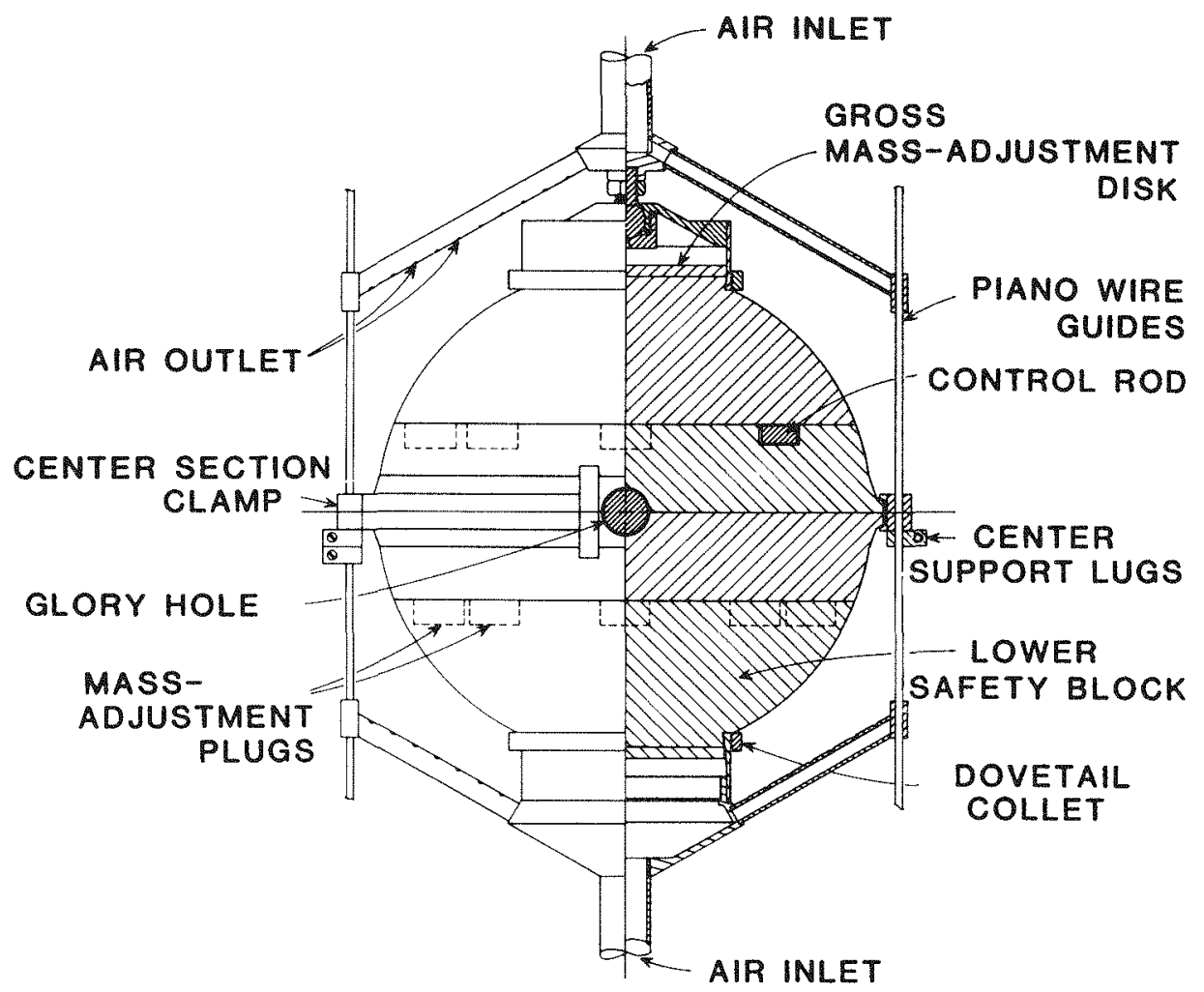

Fig. 14.

Jezebel under operating conditions. The nearly spherical assembly is supported by lightweight clamps and guides.

Leakage-spectrum measurements, by means of proton-recoil plates and external foils, were done outdoors to eliminate effects of room-return neutrons.

Two other sets of components were mounted temporarily on the Jezebel machine. 3,25 The first, of uranium metal containing $98.1 \% 233 \mathrm{U}$, was set up during 1961. A density somewhat greater than that of delta-phase plutonium led to a somewhat smaller critical mass. Measurements, particularly of reactivity contributions, were attenuated because of the intense gamma-ray activity from $232 \mathrm{U}$. With Jezebel elevated outdoors, Rossi- $\alpha$ was measured at various reactivities and proton-recoil plates were exposed. Spectral indexes were determined by means of quadruple fission chambers. Of reactivity contributions, only the $233 \mathrm{U}$ reactivity coefficient and surface value were measured.

The other set of Jezebel components was of delta-phase plutonium containing $20.1 \% 240 \mathrm{Pu}$. Operations with this material were conducted from 1964 to 1966 and in part of 1968 while normal Jezebel pieces were being reconditioned. The plutonium critical mass was $16 \%$ greater than that of the $10 \mathrm{w}-240 \mathrm{Pu}$ assembly. 25 The only other measurements that can be compared are Rossi- $\alpha$ at delayed criticality (no difference), the spectral indexes $238 \mathrm{U} / 235 \mathrm{U}\left(12 \%\right.$ greater) and ${ }^{237} \mathrm{~Np} /{ }^{235} \mathrm{U}$ (5\% greater), and the ratio of $239 \mathrm{Pu}$ to $235 \mathrm{U}$ reactivity coefficients (1\% less). 26 Production cross sections (from reactivity coefficients) of $238 \mathrm{Pu}$ and ${ }^{24} \mathrm{Cm}$ in this assembly led to estimates of critical masses of these nuclides. ${ }^{27,28}$ There were also 
reactivity coefficients of $\mathrm{CD}_{2}, \mathrm{CH}_{2}$, and carbon to give effects of hydrogen and deuterium.

Jezebel with $4.5 \% 240 \mathrm{Pu}$ was maintained for its standard spectrum through May 1977. At that time, parts required replating and have been stored since.

\section{Hydro and Exponential Columns}

The Hydro assembly was designed as a $10-\mathrm{kW}$ neutron source for uranium exponential columns (Fig. 15). It consisted of a cylindrical U(93) core with copper inserts for conducting heat to a jacket of circulating water. ${ }^{29}$ There was no upper reflector when Hydro was not in operation. Under this condition, the assembly, on a hydraulic lift, remained in a shielding enclosure outside Kiva 2. For operation, the enclosure cover was retracted and Hydro was elevated to the base of an exponential column on a sturdy support.

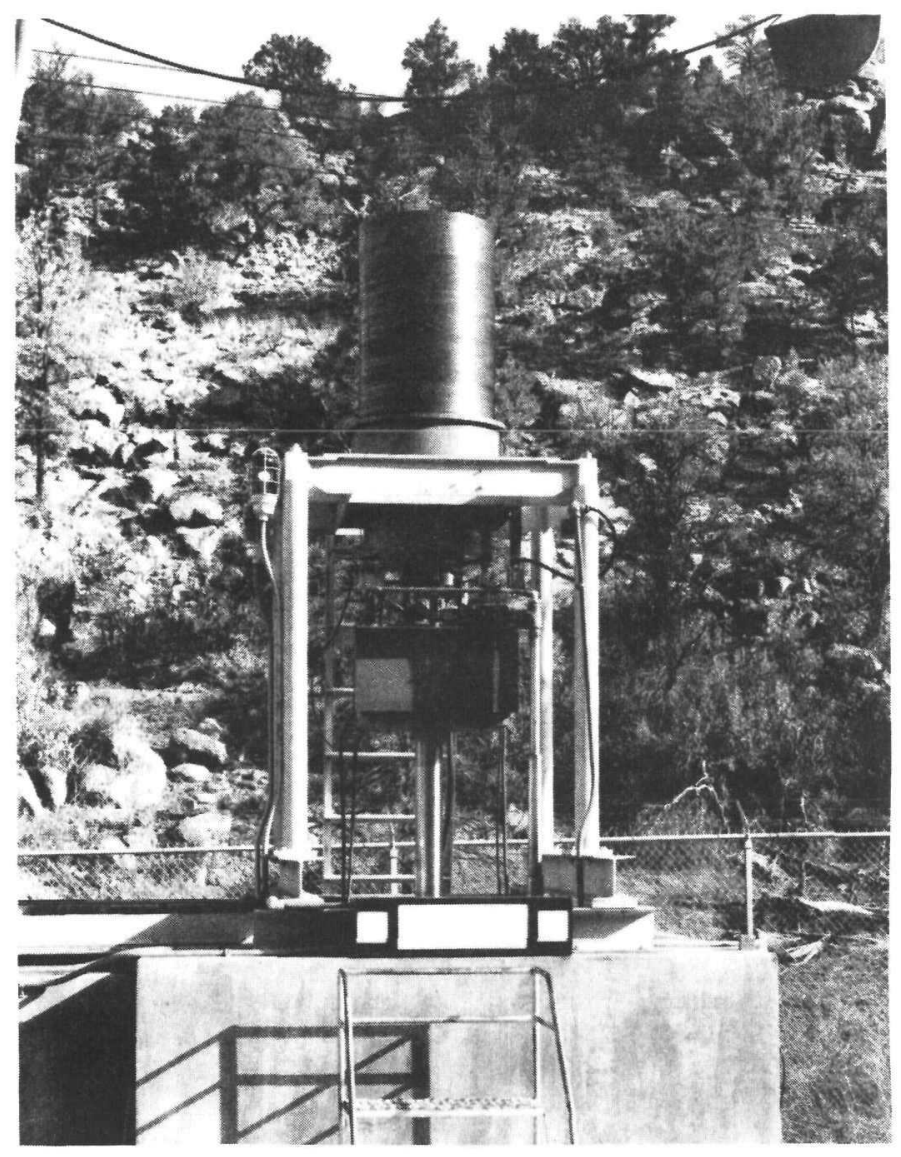

Fig. 15.

The Hydro neutron-source assembly elevated to the base of an exponential column. When the assembly is not in operation, it is retracted into the massive concrete shield. The setup was located outside Kiva 2 to eliminate the effect of room-return neutrons on the column. 
The 21-inch-diameter exponential columns ${ }^{30}$ consisted of 0.12 -inchthick plates of U(93) interleaved with various thicknesses of natural uranium, averaging $\mathrm{U}(9.12), \mathrm{U}(6.53)$, and $\mathrm{U}(4.29)$. Axial fission-rate distributions gave values of buckling, which interpolated to zero buckling at $5.5 \% 235 \mathrm{U}$ enrichment. Spectral indexes also were established. A similar experiment with a natural uranium column relates to the early Snell experiment and its successors. For example, a value of $239 \pm 7$ for $\sigma_{\mathrm{f}}(235 \mathrm{U}) / \sigma_{\mathrm{f}}(238 \mathrm{U})$ compares with the range 200 to 363 from earlier measurements. 31

The same material of the exponential columns was used to build up bare subcritical assemblies averaging $U(16.01), U(14.11), U(12.32)$, and $U(10.90)$. For each average composition, criticality was established by extrapolating to zero the neutron multiplication as a function of height. 25,32 Results led to an infinite-height enrichment of $10.5 \% 235 \mathrm{U}$ for a 21 -inch-diameter column.

\section{Miscellaneous Assemblies}

Weapon tests continued, as they do occasionally to this day. Some, including interaction measurements, were for establishing safe assembly and handling procedures. Others provided data for checking neutronic calculations. A unique measurement compared the reactivity of a weapon core in the Slotin mockup with the same core in a live weapon. It was the single exception to a practice that excludes explosives from the site. (This experiment was performed on a Sunday with few people nearby.)

Of other experiments directed specifically toward the safety of processing operations, the most extensive experiment pertained to the production of massive hemispherical U(93) shells.33 Annular and multiple crucibles for casting were investigated and the subcriticality of a $50-\mathrm{kg}$ shell was demonstrated as a guide to safe machining and handling. Plant applications were very limited because the need for massive shells turned out to be temporary.

One of the first reactor mockups, made in 1953 for the Argonne National Laboratory, was a crude representation of the proposed Experimental Breeder Reactor, EBR-II, core in a thick uranium reflector. The core composition averaged about 33 vol\% U(53.5), 52 vol\% aluminum (representing sodium), and $15 \%$ iron. The $110-\mathrm{kg} U(93)$ content was made up of Topsy blocks and Jemima plates. Critical data were transmitted directly to Argonne.

About the same time, the first mockup of a uranium-phosphate solution reactor was proposed by groups that became the nucleus of the Reactor Division at Los Alamos. It was basically a 12.5-inch-diameter cylinder containing solution in which stainless steel was distributed to simulate internal tubing. The reflector was 3 -inch-thick steel. Critical height was established as a function of phosphate concentration at about $120 \mathrm{~g}$ of U(93) per liter. This mockup, on the Planet machine in Kiva 2, was followed by a more detailed mockup on Comet in Kiva 1.

\footnotetext{
*The Snell experiment, performed in 1943, is discussed by Weinberg and Wigner in The Physical Theory of Neutron Chain Reactors, p. 720.
} 
In 1956, an assembly on Planet was directed toward the design of LAMPRE, the Reactor Division's molten-plutonium reactor. 34 The core of stacked 4.5-inch-diameter plutonium disks was reflected by approximately 2-inch-thick steel surrounded by a large thickness of water. This assembly was intended to check design calculations instead of being an actual mockup. A couple of years later a mockup of LAMPRE, including machine and controls constructed by the Reactor Division, was tested in Kiva 2. The 6 -inch-diameter core consisted of 52 vol\% plutonium, 9 vol\% tantalum, 8 vol\% stainless steel, and 31 vol\% sodium represented by aluminum at onethird density. The approximately 4-inch-thick steel reflector was surrounded by a borated-graphite shield. Controls in the reflector consisted of a large shim and a small vernier rod. Components were calibrated, and flux distributions were measured at delayed criticality.

\section{THE ROVER PERIOD}

From 1955 to 1972 , the Rover rocket-propulsion program dominated activities at Pajarito Site, 35 although weapon-related work was not neglected. While most critical measurements related to graphite-moderated Kiwi reactors, alternatives also were investigated. The most seriously considered high-temperature alternative was the Dumbo concept in which refractory metal accommodated the necessary high operating temperature. An alternative, pursued less actively, was the cavity reactor in which criticality of gaseous uranium would be maintained by a thick reflector of beryllium or $\mathrm{D}_{2} \mathrm{O}$.

During the Rover period, new critical assemblies for neutronic studies that were unrelated to the Rover Program evolved. Some assemblies were temporary, including Supercomet, a water tank for flooding tests, the Molly-G reactor destined for the White Sands Missile Range, and Thor and Ichiban assemblies on the Comet machine. Other assemblies have been retained to the present time: Flattop, a Topsy-like assembly; Godiva IV, a successor of Godiva II; and Big Ten, an assembly of uranium containing $10 \%$ $235 \mathrm{U}$.

\section{Graphite-Moderated Propulsion Reactors}

The Rover Program to develop reactors for rocket propulsion began at Los Alamos in 1955 and, during the next 17 years, intensive efforts at Pajarito Site centered on the neutronics of Rover reactors. First there were parametric surveys to provide general guidance for the designers. In these, geometric imperfections were tolerated for the sake of flexibility. Then, when overall dimensions became fixed, details of core, controls, and internal structures were established in a mockup with good geometry. Finally, the reactor destined for testing in Nevada was checked at Pajarito Site and adjusted when found to depart from specifications. With a few exceptions, this progression was followed for each new Rover reactor.

A computational capability at Pajarito Site that had been required for interpreting and supplementing critical experiments was expanded for the Rover Program. It encompassed the conversion of room-temperature critical data to high-temperature operating conditions, the detailed evaluation of radiation heating, and the calculation of shielding required in an operable rocket. 
An early Rover activity was the building of Honeycomb (Fig. 16), a horizontal split-table assembly with a matrix of square aluminum tubes in which reactor materials could be inserted. In the course of Honeycomb construction, a graphite-reflected $\mathrm{D}_{2} \mathrm{O}$ solution, Scripto, was set up because its neutron spectrum was presumed to be relevant to the Rover Program. There were two different near-equilateral eylindrical cores in 9- to 10-inch-thick graphite. The initial core contained 24.6 liters of solution at a concentration of $0.88 \mathrm{~kg} 235 \mathrm{U} / \mathrm{liter}$, the other 34.3 liters at $0.48 \mathrm{~kg}$ 235 U/liter. Scripto experiments were terminated when data from more appropriate Honeycomb assemblies became available.

Initial Honeycomb operation, early in 1956, consisted of a survey of graphite-moderated U(93) cores with beryllium reflectors. ${ }^{36}$ Cores were of $0.002-$ and 0.005 -inch-thick U(93) foils interleaved with graphite plates. This parametric study gave designers confidence in sizing proposed graphitemoderated Rover reactors.

This survey was followed by a crude Honeycomb mockup of Kiwi-A, the first reactor tested at Nevada (Fig. 17).37 A heavy-water island made

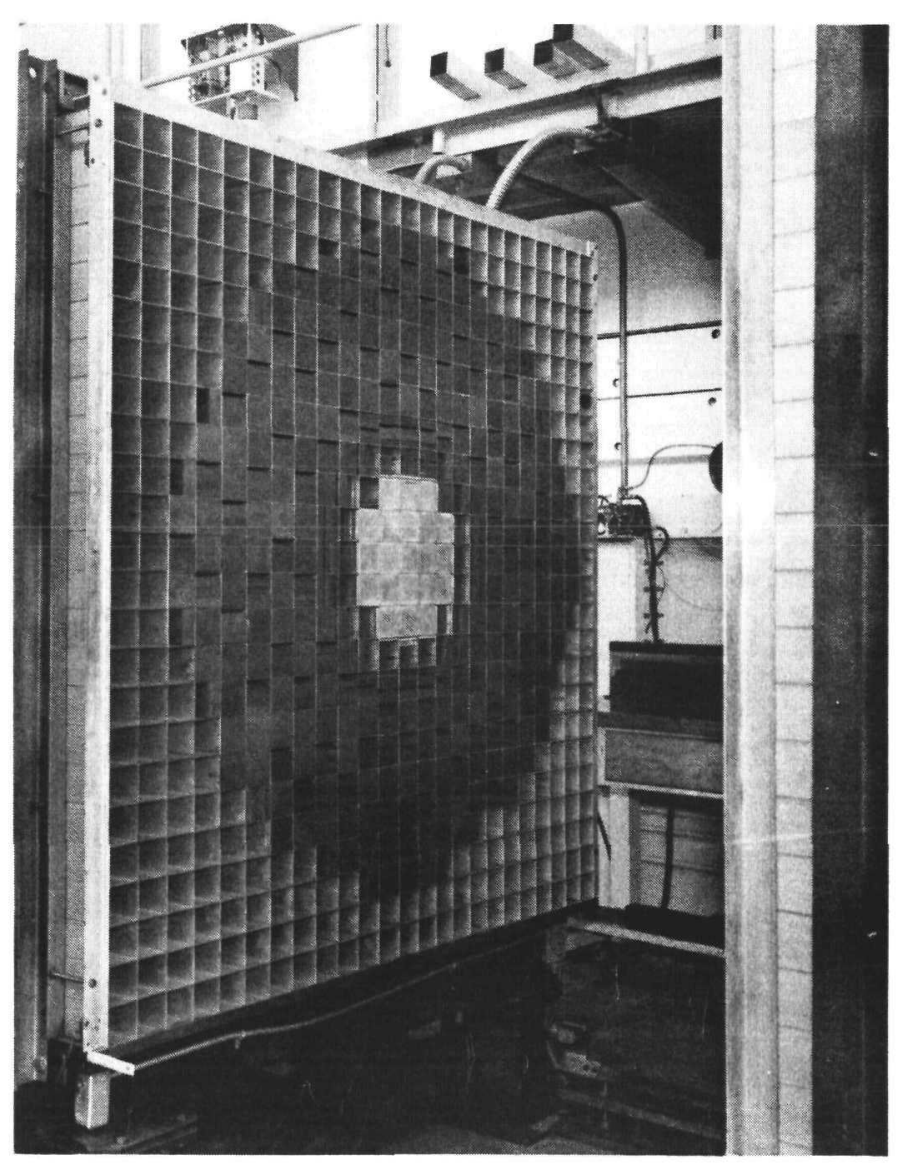

Fig. 16.

The Honeycomb assembly machine for Rover parametric surveys. The fixed portion shown contains part of the first Rover reactor. For operation, the remainder of the assembly, on tracks, joins the fixed portion. 


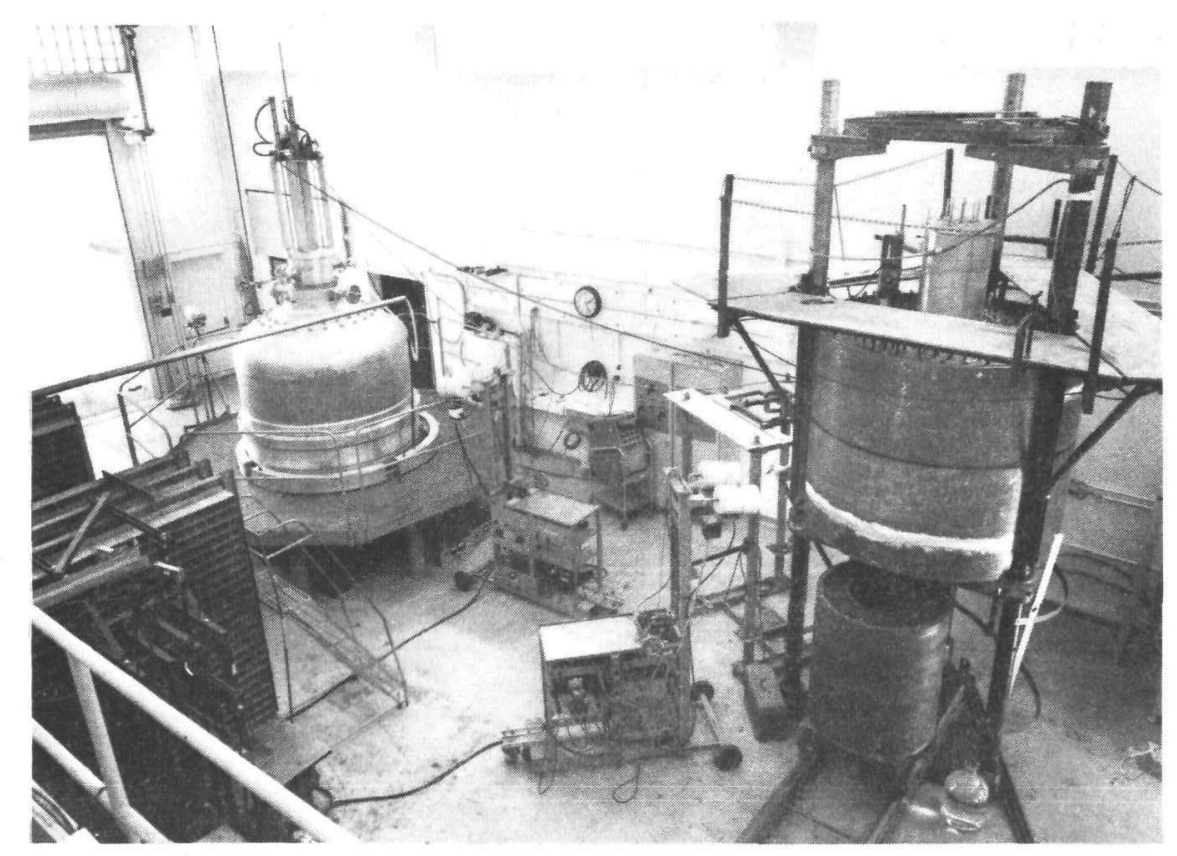

Fig. 17.

Kiwi-A, the first reactor for testing at Nevada, in Kiva l. A zero-power mockup of the same reactor (Zepo-A) appears at the right and part of Honeycomb with an earlier crude mockup is at the far left.

possible high-temperature operation without a large inventory of enriched uranium in the uranium-graphite core. Pajarito operations associated with the Kiwi-A test series (Kiwi-A, A', and A3) are typical of those conducted for most succeeding reactors destined for Nevada. Successively, there were improved zero-power mockups of the three reactors (Zepo-A, $\mathrm{A}^{\prime}$, and $\mathrm{A} 3$ ), each followed by assembly and zero-power checkout of the actual reactor before reassembly at Nevada. This sequence uncovered desirable neutronic adjustments and implemented them conveniently.

All Rover reactors tested in Nevada at design temperature and the Pajarito experiments in support of them are listed in Table I. The design of reactors listed in this table progressed as follows. In the first series, called Kiwi-A, an axial $\mathrm{D}_{2} \mathrm{O}$ island conserved enriched uranium and made possible proof-of-principle tests at a power of about $100 \mathrm{MW}$. The fuel elements, graphite loaded with uranium carbide, were distributed in a graphite matrix. Although contributing to early testing, both island and gaseous-hydrogen coolant were inappropriate for a flyable system. Severe erosion in the first test was reduced in the next two by niobium liners in the hydrogen flow channels.

In the pair of Kiwi-Bl reactors that followed, elimination of the $\mathrm{D}_{2} \mathrm{O}$ island led to a more realistic power-about $900 \mathrm{MW}$-in the second test. Of course, this was at the expense of greater enriched uranium content. Fuel rods were still distributed in a graphite matrix. Gaseous hydrogen in the first test was replaced by liquid hydrogen in the second, a further step toward a 
TABLE I

PAJARITO SUPPORT OF NEVADA TEST REACTORS

\begin{tabular}{|c|c|c|c|}
\hline Reactor & Test Date & Pajarito Mockup & Checkout \\
\hline \multicolumn{4}{|c|}{ Kiw i-A Series, $\mathrm{D}_{2} \mathrm{O}$ Island, ${ }^{\mathrm{a}, \mathrm{b}}$ Honeycomb Survey } \\
\hline $\begin{array}{l}\text { Kiwi-A } \\
\text { Kiwi-A' } \\
\text { Kiwi-A3 }\end{array}$ & $\begin{array}{l}\text { July } 1,1959 \\
\text { July } 8,1960 \\
\text { October } 19,1960\end{array}$ & $\begin{array}{l}\text { Zepo-A } \\
\text { Zepo-A } \\
\text { Zepo-A3 }\end{array}$ & $\begin{array}{l}\text { Kiva } 1 \\
\text { Kiva } 1 \\
\text { Kiva } 1\end{array}$ \\
\hline \multicolumn{4}{|c|}{ Kiwi-Bl,2 series 9-hole Cylindrical Elements, Honeycomb Survey } \\
\hline $\begin{array}{l}\text { Kiwi-Bl } A^{a} \\
\text { Kiwi-Bl } B^{d} \\
\text { Kiwi-B2A }\end{array}$ & $\begin{array}{l}\text { December } 7,1961 \\
\text { September } 1,1962 \\
\text { (test cancelled) }\end{array}$ & $\begin{array}{c}\text { Zepo-Bl Ac } \\
\text { Zepo-B2Ac }\end{array}$ & $\begin{array}{l}\text { Kiva } 3 \\
\text { Kiva } 3 \\
\text { Kiva } 3\end{array}$ \\
\hline \multicolumn{4}{|c|}{ Kiwi-B4,5,6 Series, 19-hole Hexagonal Elements (1000 $\mathrm{NWW})$} \\
\hline $\begin{array}{l}\text { Kiwi-B4D } \\
\text { Kiwi-B4E } \\
\text { Kiwi-TNTf }\end{array}$ & $\begin{array}{l}\text { November } 30,1962 \\
\text { May } 13,1964 \\
\text { August } 28 \text { and } \\
\text { September } 11,1964 \\
\text { January } 13,1965\end{array}$ & $\begin{array}{l}\text { Zepo-B4A } \\
\text { Zepo-B4B } \\
\text { Zepo-B4D } \\
\text { Zepo-B4E } \\
\text { Zepo-B5,6 }\end{array}$ & $\begin{array}{l}\text { Kiva } 3 \\
\text { (no test) } \\
\text { Kiva } 3 \\
\text { Kiva } 3 \\
\text { (no test) } \\
\text { Kiva } 3\end{array}$ \\
\hline \multicolumn{4}{|c|}{ Phoebus-1 Series, Kiwi-B4 Size, Long-life Fuel, Honeycomb Survey } \\
\hline $\begin{array}{l}\text { Phoebus-1 A } \\
\text { Phoebus-1 B }\end{array}$ & $\begin{array}{l}\text { June } 25,1965 \\
\text { June } 26,1968\end{array}$ & $\begin{array}{l}\text { Ph-l A Zepog } \\
\text { Ph-1 B Zepog } \\
\text { Ph-1 C Zepog }\end{array}$ & $\begin{array}{l}\text { Nevada } \\
\text { Kiva } 3 \\
\text { (no test) }\end{array}$ \\
\hline \multicolumn{4}{|c|}{ Phoebus-2 Reactor (5000 MW), Enlarged Honeycomb Survey } \\
\hline Phoebus-2A & June 26,1968 & $\begin{array}{l}\mathrm{Ph}-2 \text { Zepo h } \\
\text { Ph-3 Zepo h }\end{array}$ & $\begin{array}{l}\text { Kiva } 3 \\
\text { (no test) }\end{array}$ \\
\hline \multicolumn{4}{|c|}{ Pewee Series, ZrH Moderation, 500-MW Fuel Test, Pewee Survey } \\
\hline $\begin{array}{l}\text { Pewee-1 } \\
\text { Pewee-2 }\end{array}$ & $\begin{array}{l}\text { November } 21,1968 \\
\text { (test cancelled) }\end{array}$ & $\begin{array}{l}\text { PW-1 Zepo } \\
\text { PW-2 Zepo } \\
\text { PW-3 Zepo }\end{array}$ & $\begin{array}{l}\text { Kiva } 3 \\
\text { Kiva } 3 \\
\text { (no test) }\end{array}$ \\
\hline \multicolumn{4}{|c|}{ Nuclear Fuel Furnace, Water Moderation, 50-MW Fuel Test } \\
\hline$N F-1$ & $\begin{array}{l}\text { June } 29 \text { and } \\
\text { July } 12,21,27,1972\end{array}$ & $\begin{array}{l}\text { NF-1 Zepoh } \\
\text { NF-2 Zepoh }\end{array}$ & $\begin{array}{l}\text { Kiva } 3 \\
\text { (no test) }\end{array}$ \\
\hline
\end{tabular}

a Graphite reflector, all others beryllium.

bGaseous hydrogen feed, all others liquid hydrogen.

COn the Venus machine in Kiva 1.

dFuel ejected.

ecore vibration.

f Destructive test.

gModification of $\mathrm{Parka}$, a Kiwi-B4 reactor installed in Kiva 3 as a critical assembly.

hon the Mars machine in Kiva 1. 
flyable system. Liquid hydrogen remained the coolant-propellant in all succeeding tests.

The technology used to produce fuel elements of the ultimate form was fascinating. The 132-cm-long hexagonal rods, $1.9 \mathrm{~cm}$ across, each contained 19 precisely located flow channels-a production feat. These elements were packed together as cores of the Kiwi-B4 series and succeeding reactors (the last Nevada reactor was an exception). A niobium coating on element surfaces controlled corrosion, but a more serious problem was encountered in the first test. Vibration led to the fracturing of fuel elements and ejection of pieces. The cure, a different design of core constraint, was confirmed by satisfactory behavior during the next two tests of this series. Restart capability and 10-minute operation at about $1000 \mathrm{MW}$ were demonstrated.

Puzzling behavior of the first Kiwi-B4 reactor was encountered during its checkout at Pajarito Site. Contrary to results with mockups, the system was too reactive to be completely assembled as designed. For proper operation, it was necessary to replace some fuel by inert material and to introduce neutron poison. Ultimately, the extra reactivity was traced to hydrolysis of the uranium carbide distributed as particles throughout the graphite fuel matrix. The source was moisture in the air. Starting later in the Kiwi-B4 series, hydrolysis was eliminated by distributing the uranium carbide as small beads with a protective coating.

The final reactor of this class, Kiwi-TNT, with a special arrangement to increase reactivity very rapidly, was purposely destroyed to simulate a reactivity accident (Fig. 18). This served to check the required accident analyses, thereby increasing confidence in yield calculations.

Before going to Nevada, the Kiwi-TNT reactor was involved in a unique series of experiments at Pajarito Site. It and the similar Parka reactor, positioned close together (Fig. 19), were operated simultaneously to measure their interaction. 38 This information was needed for estimating the effect of clustering several reactors to power a single high-thrust rocket.

Refinements for flyable systems were introduced in the Nevada tests of the next two reactors, designated Phoebus-1. These reactors were of Kiwi-B4 size and general design. Improved fuel led to increased power density and duration of operation. More specifically, the second test demonstrated $30-$ minute operating time at about $1500 \mathrm{MW}$, and a propellant exhaust temperature of $2500 \mathrm{~K}$.

The final test of a potentially flyable reactor, Phoebus-2, was directed toward increased power and thrust. To attain this goal, the core size was increased (to contain 4000 fuel elements); otherwise, the design was generally like that of Phoebus-1. In Nevada, power greater than $4000 \mathrm{MW}$ was attained.

The final two Los Alamos reactors operated in Nevada, Pewee and Nuclear Fuel Furnace, were designed specifically for relatively inexpensive testing of improved fuel elements. Again, they were inappropriate for flyable systems. Although Pewee contained just 400 elements, one-quarter the number in Phoebus-1, test of a second version was cancelled in 1971 because of funding restrictions. The power density attained in Pewee-1, $5 \mathrm{MW} /$ liter of fuel, was the greatest observed. It was still possible to test 


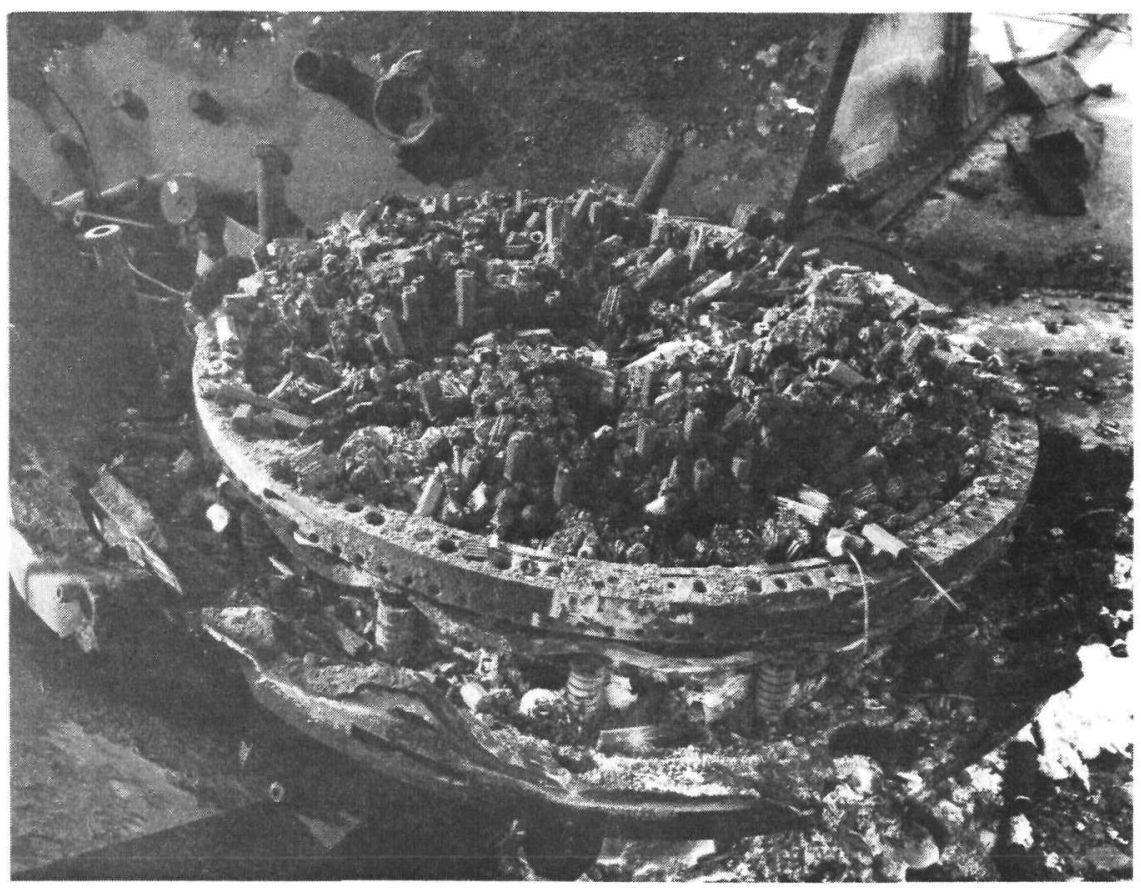

Fig. 18.

Remnant of Kiwi-TNT on test stand after the planned destructive excursion.

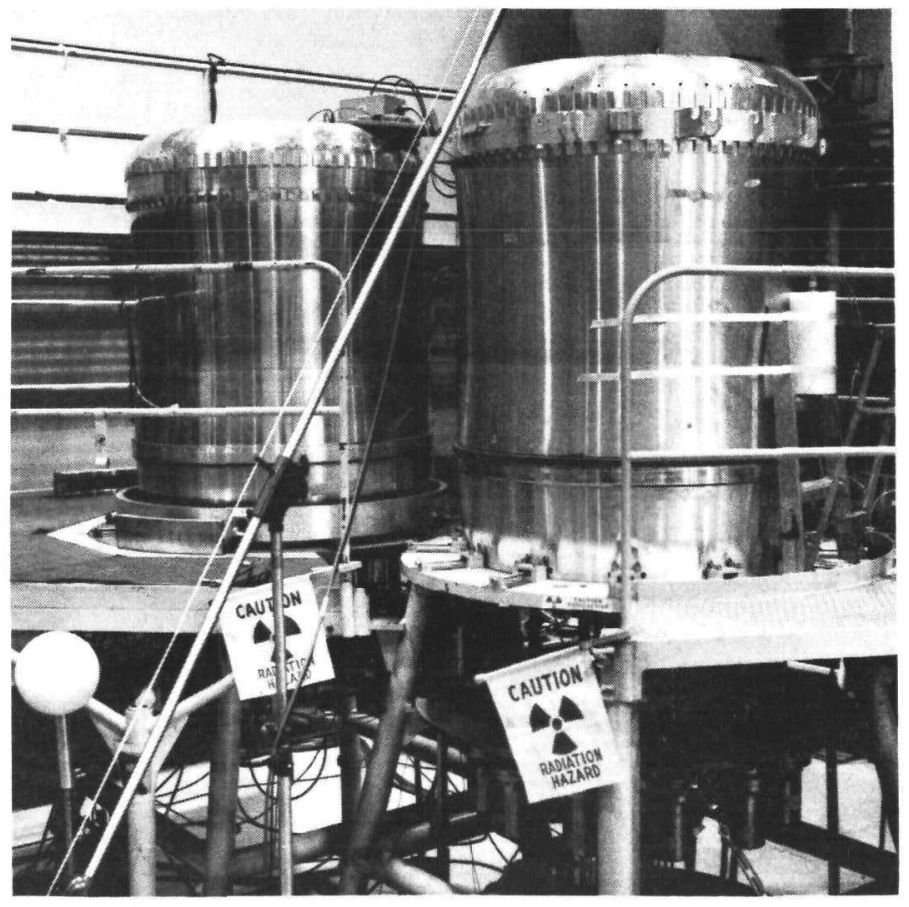

Fig. 19.

The Kiwi-TNT and Parka reactors in Kiva 3 for simultaneous operation to establish interaction at various separations. 
the much smaller Nuclear Fuel Furnace the next year (only 49 elements with water moderation), but the entire program was cancelled 18 months later.

In 1960, a third kiva became operational to share Rover activities. Measurements at Pajarito Site were paralleled by a comprehensive computational program. 39-48 Further, Pajarito personnel assisted with diagnostic measurements at Nevada and the conduct of tests. 49

Detailed neutronic information required of Pajarito tests included control-drum calibration, fuel-loading distribution to approximate constant radial fission density, reactivity effects of hydrogen propellant and niobium coating (to prevent reaction with core graphite), and effects of heat shield and beryllium reflector modifications. With the adoption of 19-hole fuel elements, a restricting orifice was inserted at the entrance of each flow channel to provide uniform outlet temperature during high-temperature operation. The orificing recipe depended upon detailed power-distribution measurements in Zepo assemblies and preassembled reactors. In the case of Phoebus-2A, with 4000 fuel elements, the recipe applied to each of 76000 flow channels (Fig. 20). 50

It was necessary to translate neutronic data at ambient temperature to corresponding data at operating temperatures that peaked at about $2500 \mathrm{~K}$. This called for detailed neutronic calculations that were checked against Nevada test results as they became available.51,52 Other types of calculations by the critical experiments group at Pajarito Site applied to

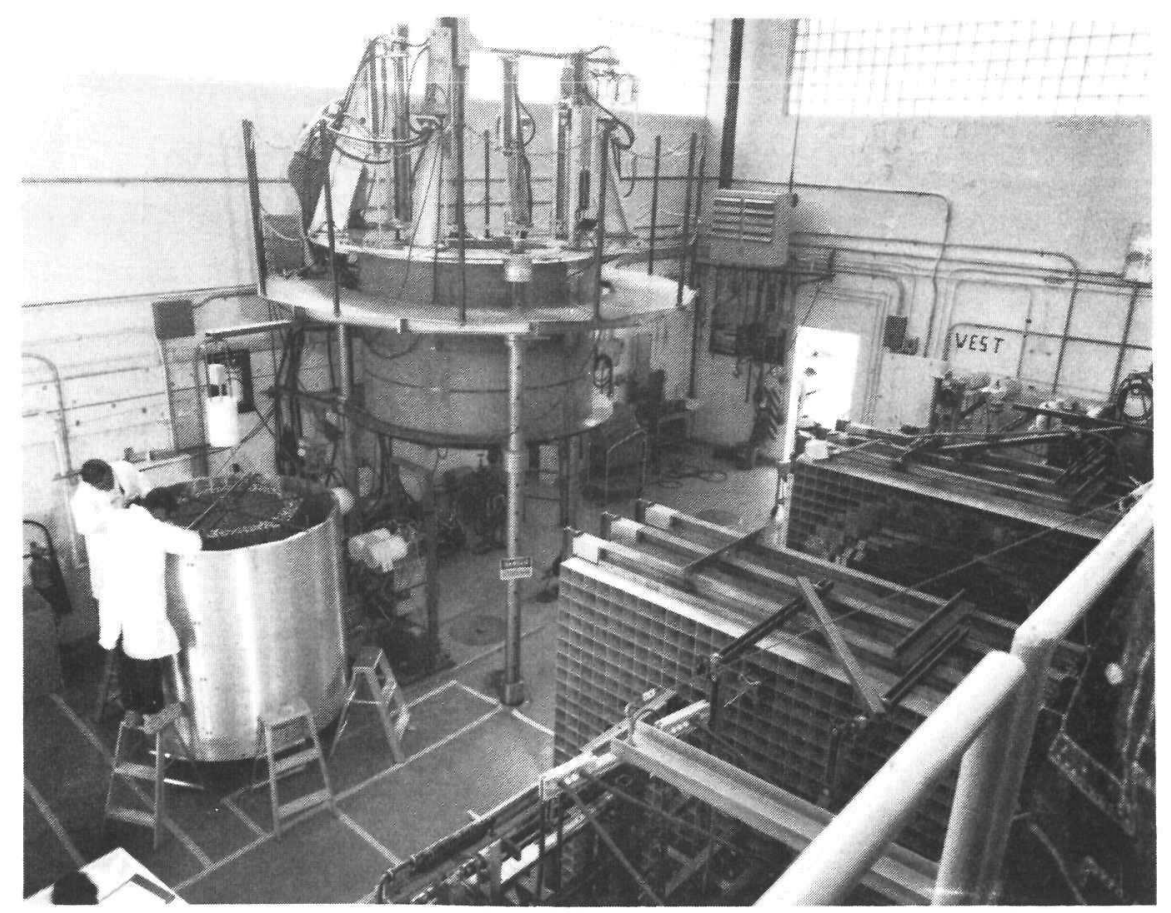

Fig. 20.

The core, with 4000 fuel elements, being assembled in the zero-power mockup of the Phoebus-2 reactor. A much cruder simulation of the same reactor is in the Honeycomb machine at the right. 
radiation transport, its local heating effects, and shielding requirements. $43,44,48$ Until Rover's termination in 1972 , the graphite-moderated reactor program was intensive.

\section{Dumbo Reactors}

The most serious proposal for an alternative to graphite-moderated Rover reactors was called Dumbo. The concept was intended to take advantage of the high-temperature characteristics of the refractory metals, most notably tungsten, with tantalum and molybdenum also in consideration. Annular $\mathrm{W}-\mathrm{UO}_{2}$ fuel columns, distributed within a hydrogenous moderator, were sized such that a good proportion of neutrons would pass over capture resonances in the course of slowing down. Liquid hydrogen in the moderator region would be heated while diffusing into fuel column annuli and would be exhausted along the axes.

Initial Dumbo mockups consisted of a 25-inch-diameter polyethylene cylinder with thirty-seven 3-inch-diameter holes to contain various simulations of fuel columns. The assembly was known as Aunt Polly (Fig. 21). Aluminum and graphite structures supported tungsten and U(93) foils within the holes. Some assemblies had lateral beryllium reflectors up to 6 inches thick. Principal measurements established quantities of $\mathrm{U}(93)$ or thicknesses of beryllium to of fiset effects of added tungsten, effects of molybdenum replacing tungsten, and fission-rate traverses.

When Honeycomb became available, a greater variety of assemblies in that machine replaced Aunt Polly. Stages in the design of Dumbo-A, intended for testing at Nevada, were mocked up successively in Honeycomb. Molybdenum replaced tungsten in this design because it is more amenable to fabrication as fuel containing $\mathrm{UO}_{2}$ and as spacers in fuel columns. Finally, Zepo Dumbo-A, a close mockup of the test design, was taken to criticality in Kiva 1 . At this stage, in 1959, effort on Dumbo was abandoned because of design problems (such as nonuniformity of hydrogen flow into fuel columns), and failure to show advantages over Kiwi-type reactors.

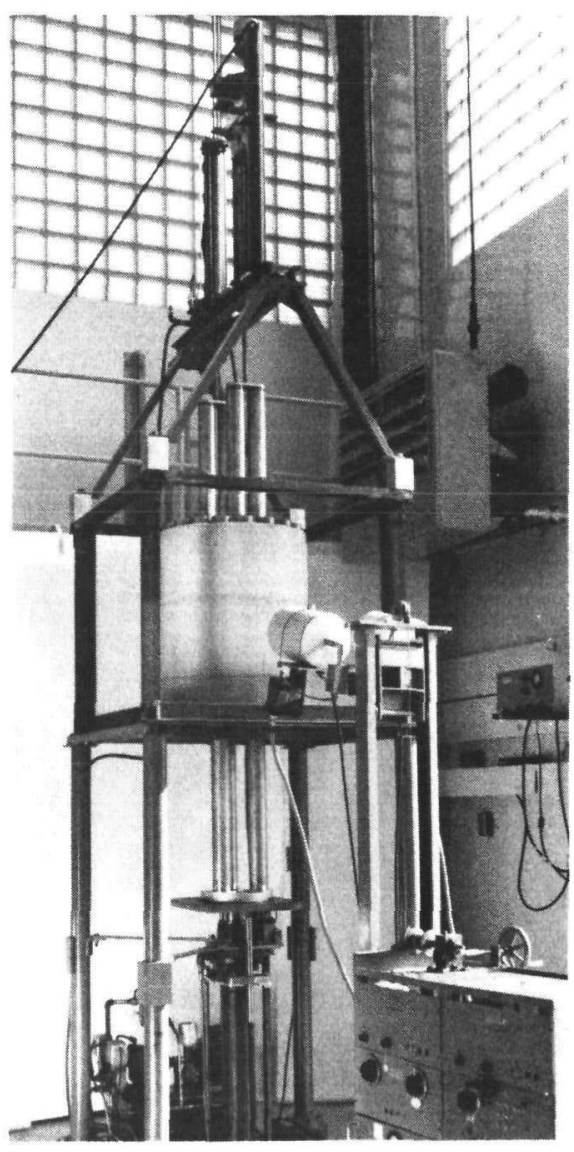

Fig. 21.

The Aunt Polly mockup of the proposed Dumbo propulsion reactor. 
A way-out alternative to Kiwi, the cavity reactor, led to no intensive effort. Instead, a few simplified versions were shoehorned into the Rover Program. 53 The reactor concept had a critical quantity of gaseous uranium inside a thick moderating reflector such as $\mathrm{D}_{2} \mathrm{O}$ or beryllium. The heated uranium, even as a plasma, was to be confined and the container wall insulated by a vortex of inert gas. Hydrogen propellant was to be heated either by passage through the core or by radiation from the plasma.

The first simplified version (Fig. 22) in Kiva 2 used a 40-inch-equilateral cavity in 20-inch-thick $\mathrm{D}_{2} \mathrm{O}$. Uranium gas was simulated either by U(93) foil lining the cavity or Rover fuel distributed uniformly, peripherally, or clustered about the axis. The minimum eritical mass, $5.8 \mathrm{~kg}$ of U(93), was with the foil liner.

Other eavity assemblies, in Kiva 1, made use of Rover beryllium as reflector material (Fig. 23). Two thicknesses of beryllium (one about 15 inches, the other about 18 inches) surrounded a 30-inch-high cavity 15 inches in diameter. Again, either U(93) foil lined the cavity or Rover fuel

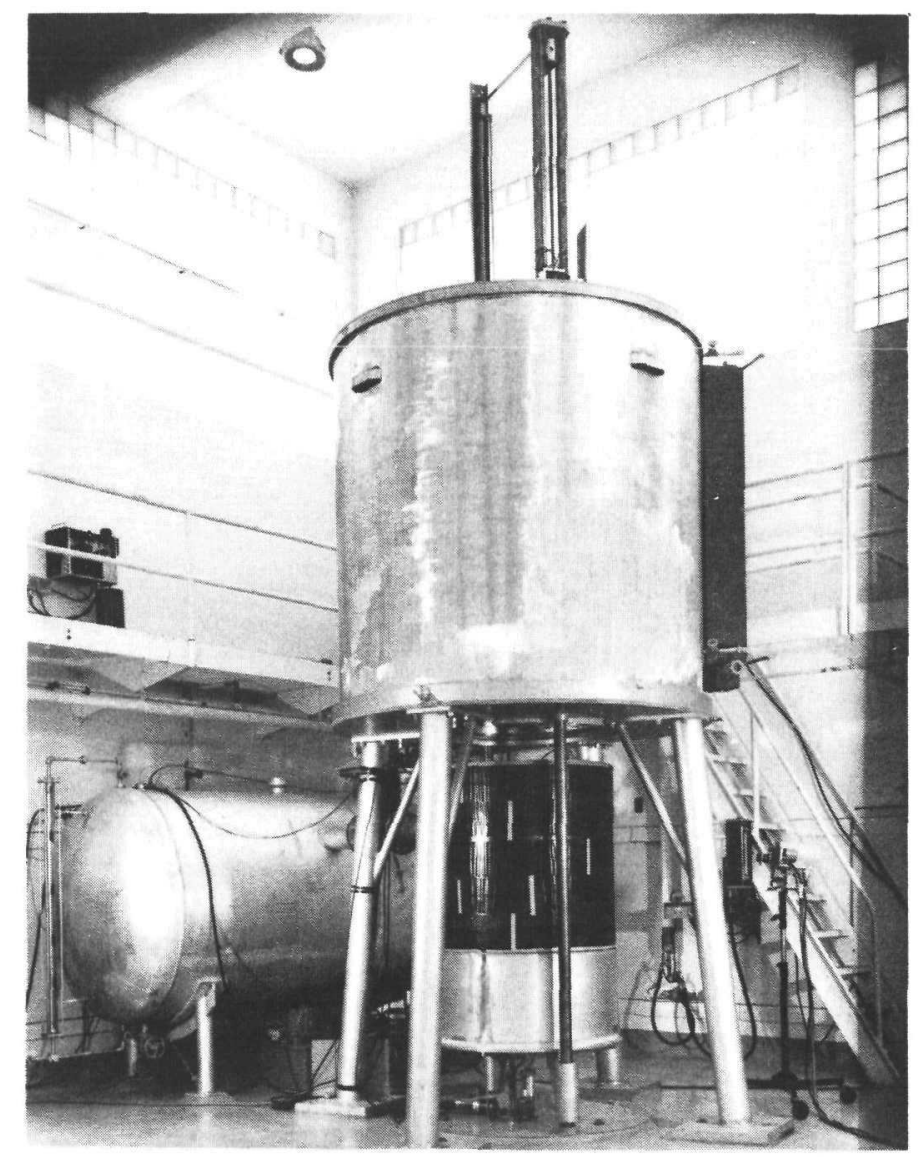

Fig. 22.

The $\mathrm{D}_{2} \mathrm{O}$ Cavity Assembly in Kiva 2. A liner of thin U(93) foil, standing on a tank of $\mathrm{D}_{2} \mathrm{O}$, is raised into a cavity within the principal $\mathrm{D}_{2} \mathrm{O}$ reflector. 


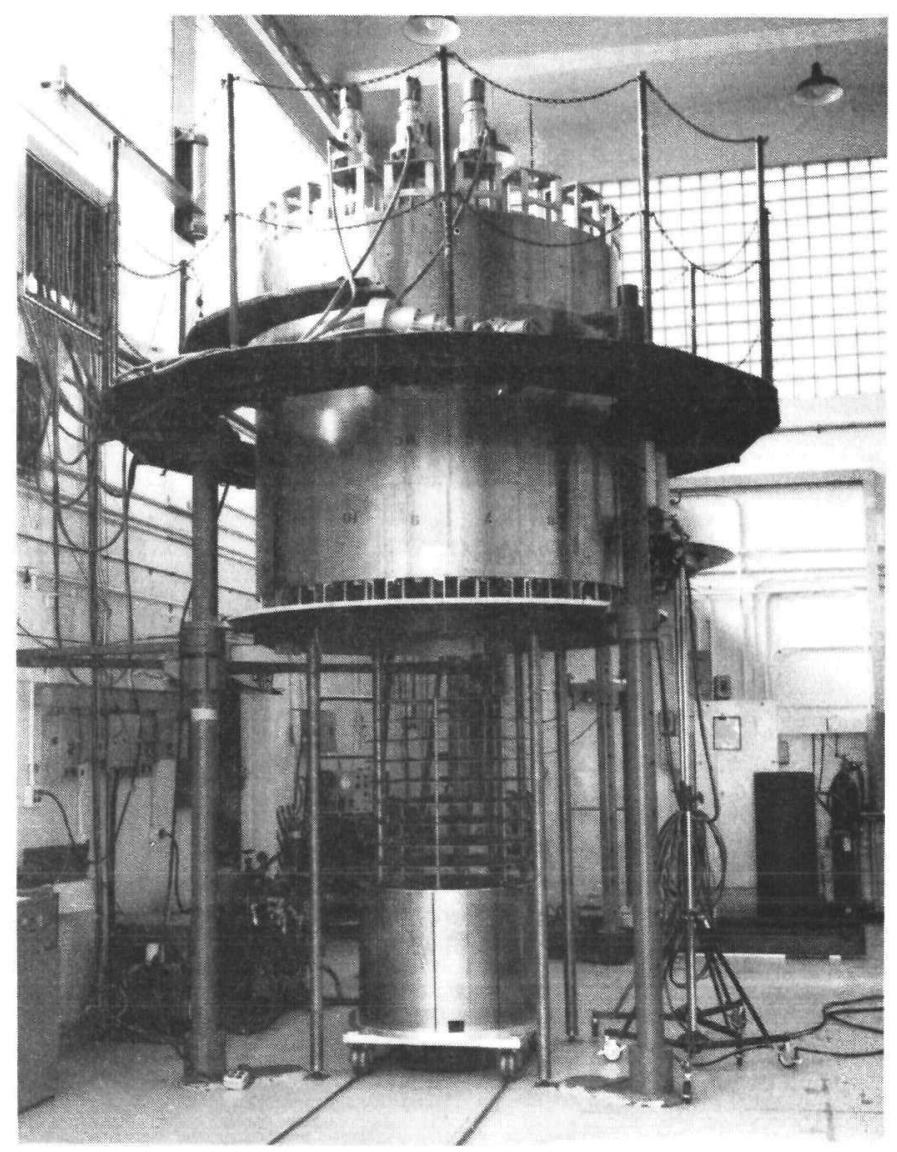

Fig. 23.

A beryllium-reflected cavity assembly set up in Kiva 1 as a preliminary to the Plasma Core Assembly.

elements were distributed as in the $\mathrm{D}_{2} \mathrm{O}$ assemblies. Minimum critical masses were $10.1 \mathrm{~kg}$ of $\mathrm{U}(93)$ in the thin reflector and $8.3 \mathrm{~kg}$ in the thick reflector, with peripheral Rover fuel in each case. (In this small cavity, foil liners were too thick to be as effective as the fuel elements.)

After termination of the Rover Program, another cavity assembly system, the Plasma Core Assembly (Fig. 24), was set up in Kiva 1 as part of a National Aeronautics and Space Administration (NASA) program. 54 By using the Phoebus-2 reflector in the Plasma Core Assembly, the $\mathrm{D}_{2} \mathrm{O}$ Cavity Assembly was approximated with beryllium as reflector. Actually the reflector thickness was about 1 inch less than for $\mathrm{D}_{2} \mathrm{O}$. The minimum critical mass with distributed U(93) foil was surprisingly large, $19 \mathrm{~kg}$.

The critical mass was reduced to $7.7 \mathrm{~kg}$ of $\mathrm{U}(93)$ with a beryllium cylinder inside a liner of Rover fuel rods. Small quantities of gaseous $\mathrm{UF}_{6}$ were introduced on the axis of this assembly, first statically, then as flowing gas confined within an argon vortex. ${ }^{55}$ The maximum quantity of $\mathrm{UF}_{6}$ contributing to criticality was $50 \mathrm{~g}$ under flowing conditions. 


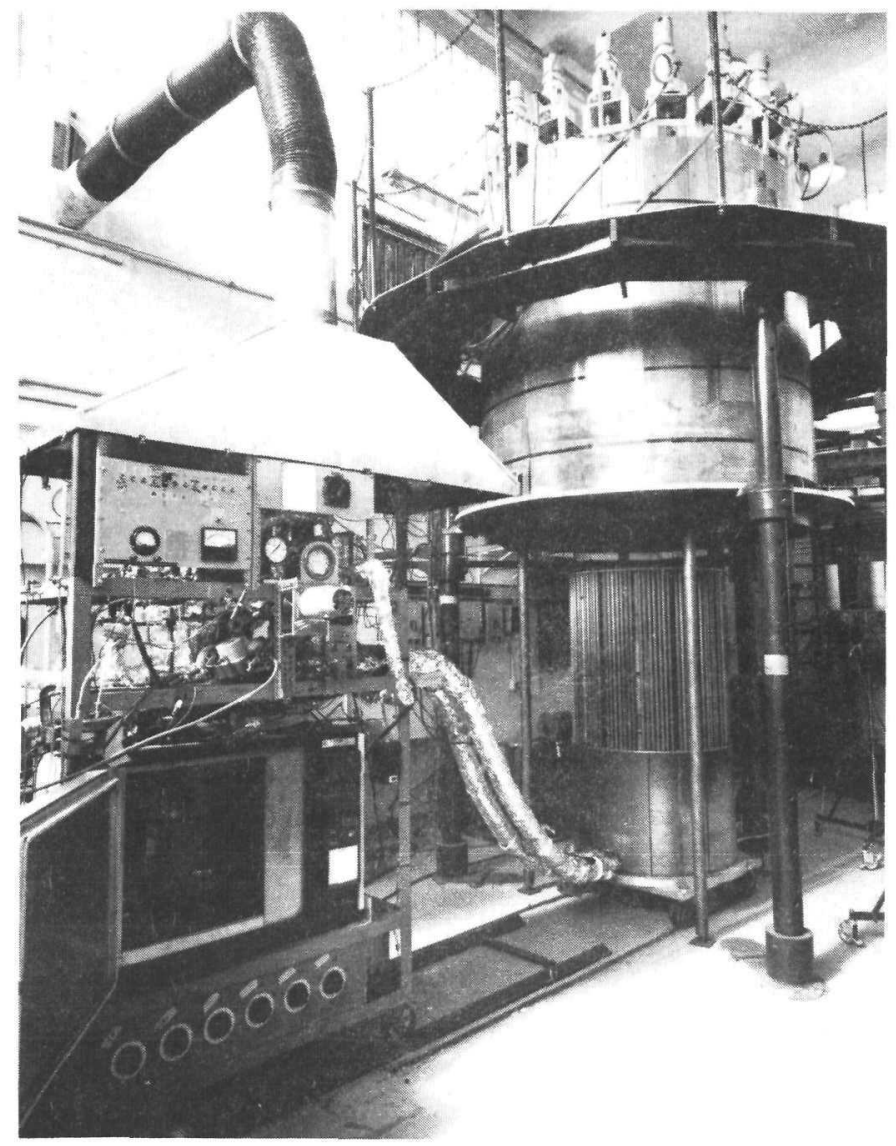

Fig. 24.

The Plasma Core Assembly with flowing $\mathrm{UF}_{6}$ system at left.

\section{Temporary Assemblies}

Supercomet, a vertical lift machine with greater travel than Comet, was installed temporarily in Kiva 3 and was used primarily for a mockup of a so-called plasma thermocouple reactor. The reactor was to consist of many cells containing $235 \mathrm{U}$, each of which would establish an electromotive force as a result of fission. Water moderation of the cells would lead to criticality. The purpose was to power a low-thrust ionic propulsion system for space exploration. The proposal did not pass the study stage.

Other new non-Rover machines or assemblies from 1955 to 1972 were in Kiva 2 with the exception of Godiva IV, which is discussed later. One such assembly, also temporary, was a tank with adjustable water level for flooding tests. It established the safety of immersed weapon components, poisoned arrays of Rover fuel elements, and even the prompt-burst assembly, Godiva II.

Another operation involved Molly-G (Fig. 25), now known as the White Sands Missile Range Fast Burst Reactor. This Godiva-type system was checked out and calibrated in Kiva 2 before shipment to its ultimate location. 


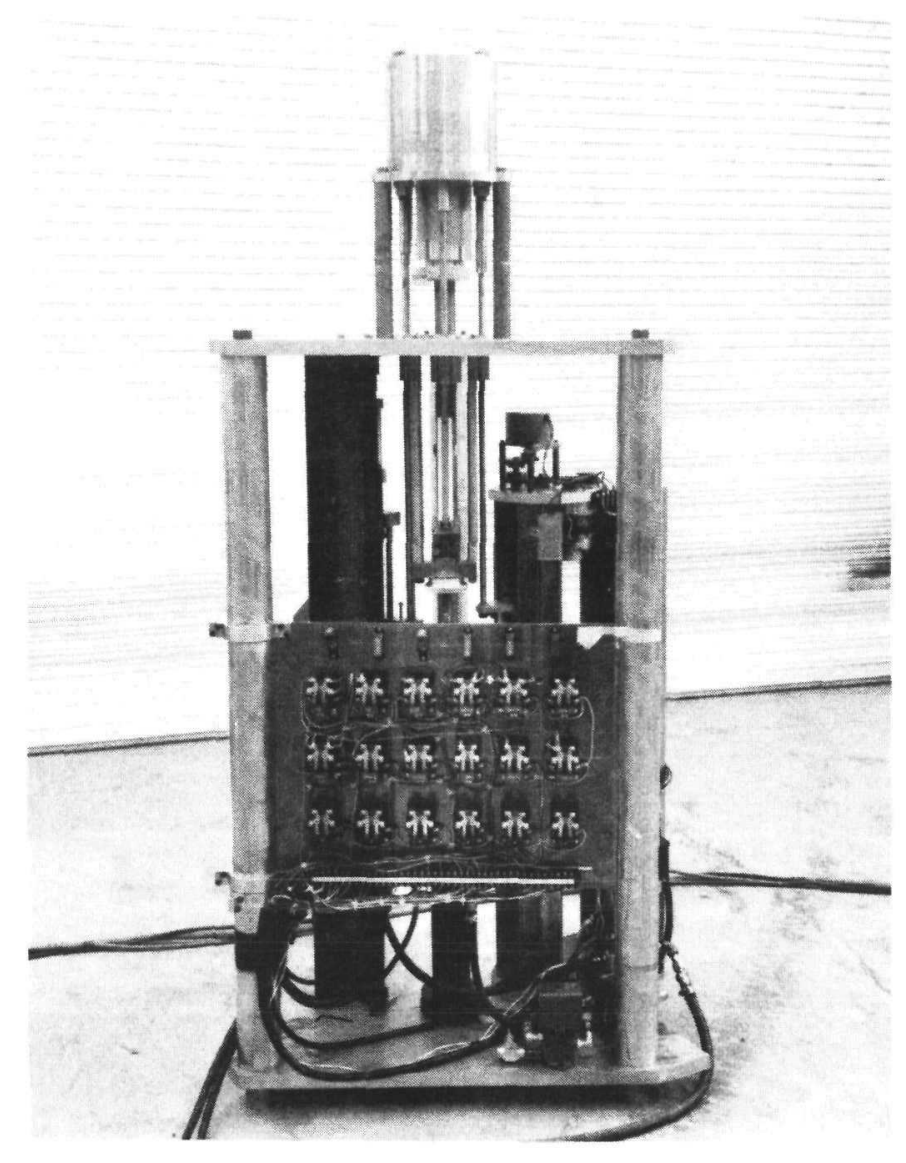

Fig. 25 .

Molly-G, the White Sands Missile Range fast-burst reactor in Kiva 2 for checkout. It is similar to Godiva II.

Several special assemblies were mounted on Comet. One was a mockup of the Livermore Super Kukla fast-burst reactor, whose unique feature is a 24-inch-high irradiation cavity 18 inches in diameter. Another critical assembly was Thor, ${ }^{56}$ a thorium-reflected plutonium sphere (Fig. 26). Yet another assembly tested on Comet was Ichiban, an assembly with nuclear characteristics similar to the Hiroshima weapon. Oak Ridge personnel measured the neutron fluence and dose leakage, gamma-ray dose leakage, and neutron spectra from Ichiban to help construct the air-dose versus distance relationship pertaining to Hiroshima.57 The other noteworthy assembly on Comet was U(93) foil moderated by polyethylene and reflected by beryllium. With $0.003-\mathrm{cm}$-thick foil the critical mass, $0.29 \mathrm{~kg}$ of ${ }^{235} \mathrm{U}$, is the smallest attained experimentally. 58

\section{Flattop}

Topsy's successor, Flattop (Fig. 27) is still operational. It uses spherical geometry instead of the more flexible pseudospherical structure that was appropriate when critical masses were not well established. A massive bed supports a 19-inch-diameter natural uranium sphere of which one hemisphere is stationary. Two quadrants of the movable hemisphere travel on guiding 


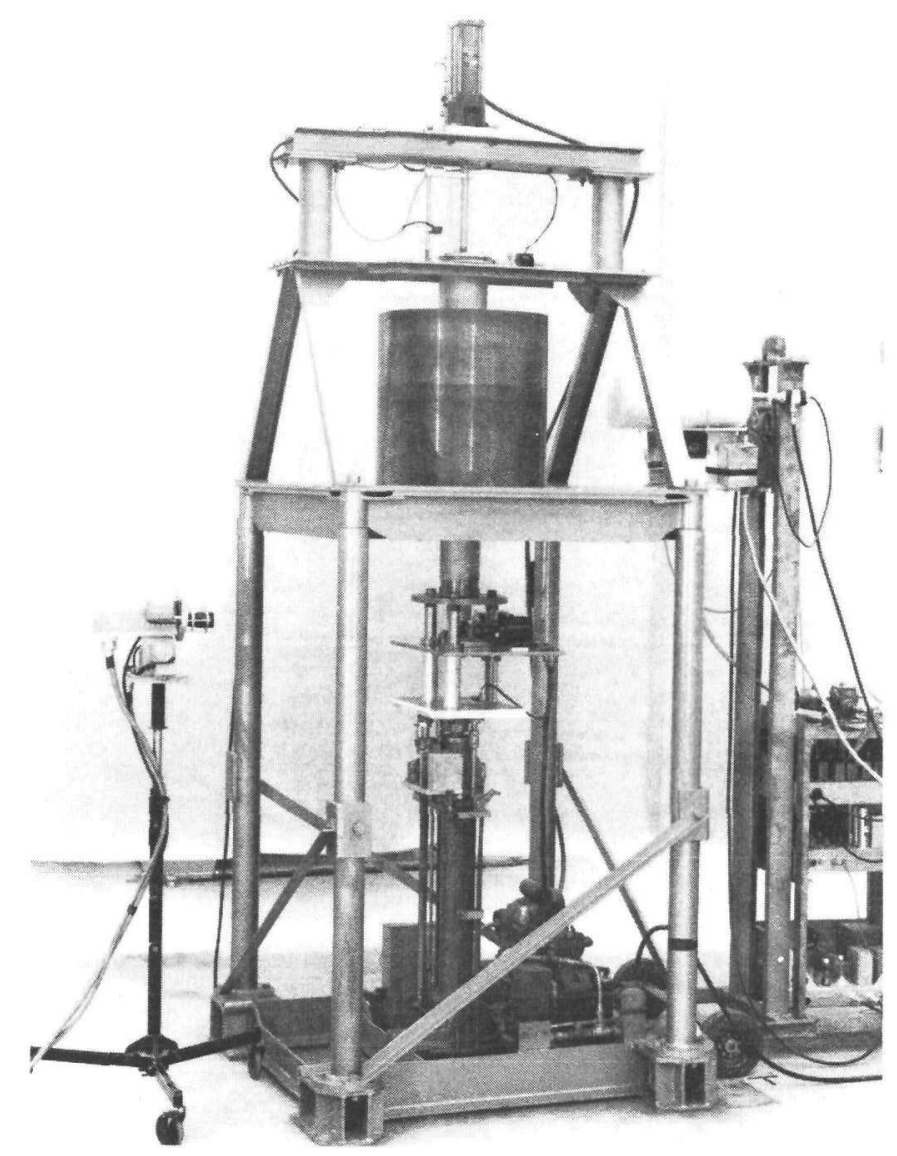

Fig. 26.

Thor, a thorium-reflected plutonium sphere on the Comet assembiy machine.

ways such that a spherical central core on a pedestal is accessible to personnel except during operation. Natural uranium adapters are sized tor cores of $\mathrm{U}(93), 239 \mathrm{Pu}$, and $233 \mathrm{U}$. Thin mass adjustment buttons of core material can replace natural uranium in the adapters to compensate for incomplete filling of the glory hole.

The three basic cores, with corresponding bare assemblies Lady Godiva and Jezebel, round out the fissile isotopes, ${ }^{235} \mathrm{U},{ }^{239} \mathrm{Pu}$, and ${ }^{233} \mathrm{U}$, with and without effective uranium reflectors. 25 Flattop has also been adapted to composite cores of U(93) and plutonium. 59

\section{Godiva IV}

Fast-burst assemblies such as Godiva II were subject to reactivity change due to shock deformation of the mounting structure. Godiva IV60 was designed to eliminate this difficulty by taking up the shock in a strong, heavily sprung retainer for the principal fissile components (Fig. 28). This retainer is mounted at centers of shock such that stress is not transmitted to the support. The retainer consists of three massive C-clamps holding the reactor head between two heavy rings, one of which is recessed to take up 


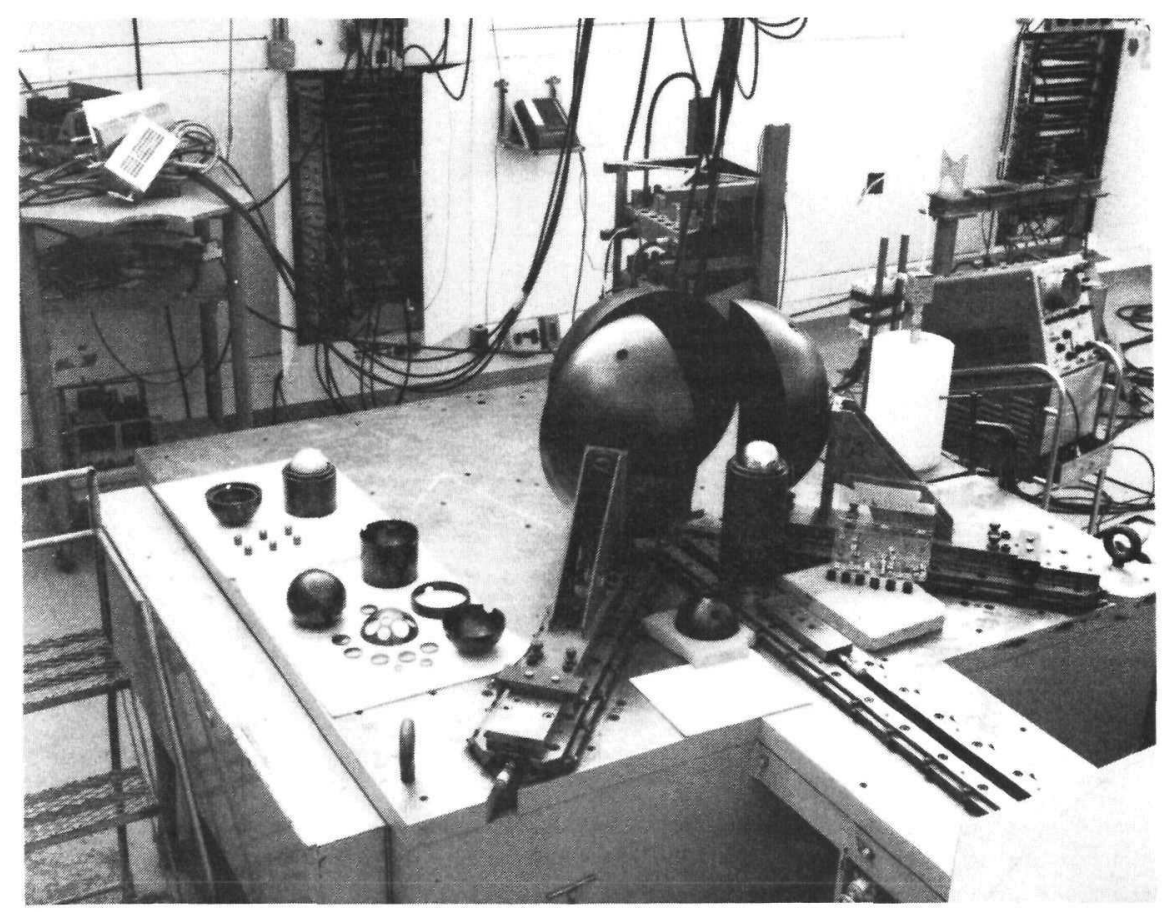

Fig. 27.

Flattop, with a plutonium core on the pedestal. The $\mathrm{U}(93)$ and $233 \mathrm{U}$ cores with adapters and mass-adjustment inserts are at the left. For operation, with adapter in place, the pedestal is retracted into the stationary reflector hemisphere, and the two reflector quadrants (on ways) are moved against the hemisphere.

shock. Pulses of $6 \times 10^{16}$ fissions (30 microseconds width at half-height) are produced regularly without damage to the U(93)-2\% molybdenum rings that constitute the reactor head (Fig. 29). Damage threshold appears to be about $8 \times 10^{16}$ fissions. Godiva IV, in Kiva 3, remains the most active assembly at Pajarito Site.

\section{$\underline{\text { Big Ten }}$}

Structural materials in critical assemblies directed toward fast-reactor design introduce uncertainties in neutronic analysis. To help resolve these uncertainties, Big Ten, 61 an all-uranium assembly, was constructed with a core at reasonably low $235 \mathrm{U}$ enrichment (Fig. 30 ). The result is a 21-inch-diameter cylindrical core averaging $U(10)$ in a 6-inch-thick natural uranium reflector, mounted on a split-table machine. The core length was adjusted to 22.6 inches for kinetic measurements ( 86 cents excess reactivity) and reduced to 21.4 inches (18 cents excess reactivity) for measurements near delayed criticality. ${ }^{*}$

\footnotetext{
${ }^{*}$ The dollar, or 100 cents, is a unit of reactivity defined as the interval between delayed criticality (steady state) and prompt criticality (the runaway condition).
} 


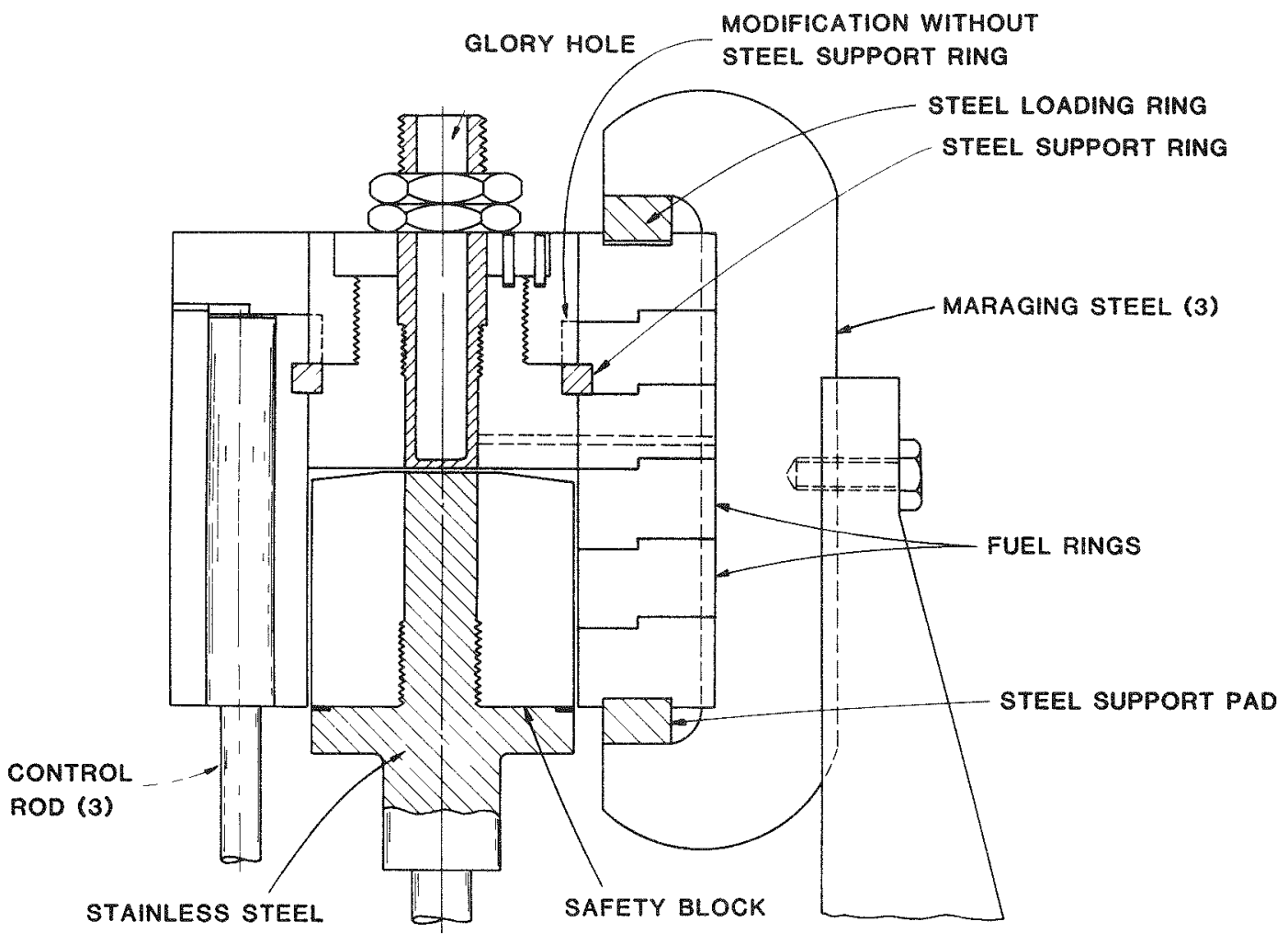

Fig. 28.

The Godiva IV design for center-of-shock mount. The steel loading ring is recessed beneath each of three C-clamps, but is in contact with the upper fuel ring between them. It thus serves as an extremely stiff spring for resisting shock displacement.

The core consists of axial components of $U(10)$ metal surrounded by interleaved plates of $U(93)$ and natural uranium such that the average enrichment is $10 \% 235 \mathrm{U}$. The $\mathrm{U}(10)$ components are intended to smooth effects of structure on axial measurements. Control by means of natural uranium rods in the reflector is sufficient for operation near delayed criticality, but an axial shim rod was added for kinetic measurements (Fig. 31).

Inconsistency between reactivity calibrations by positive-period and Rossi- $\alpha$ measurements had been claimed for some fast-neutron systems, but was not encountered in our small very-fast assemblies. Thus, a main objective of kinetic measurements was to compare calibrations by the two methods. In brief, no inconsistency was encountered between 6 and 83 cents supercritical. Central reactivity coefficients and spectral indexes are of interest primarily as a check of cross-section sets for reactor calculations and as a possible contribution to improving those sets.

\section{SINCE 1972}

For 5 years following the termination of Rover, the critical experiments group became increasingly involved with projects directed toward a plasma core power reactor for NASA. Otherwise, experiments continued on the 


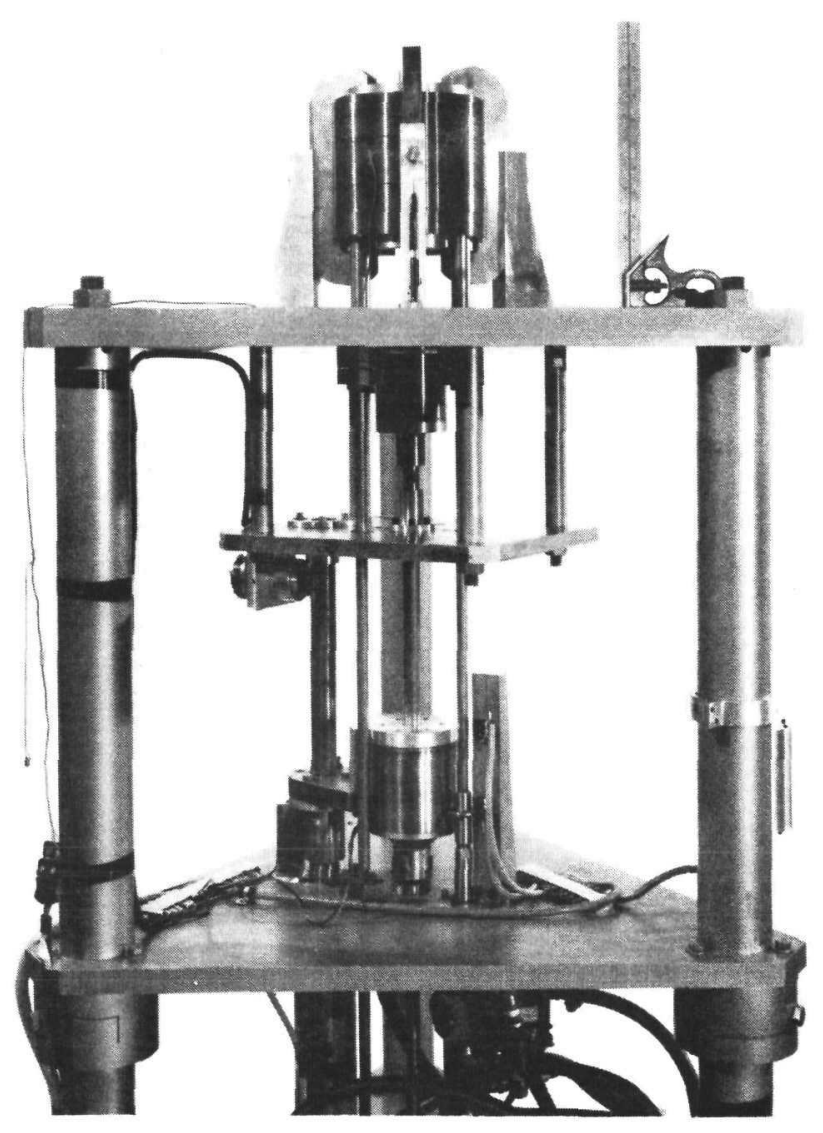

Fig. 29.

The Godiva IV fast-burst assembly.

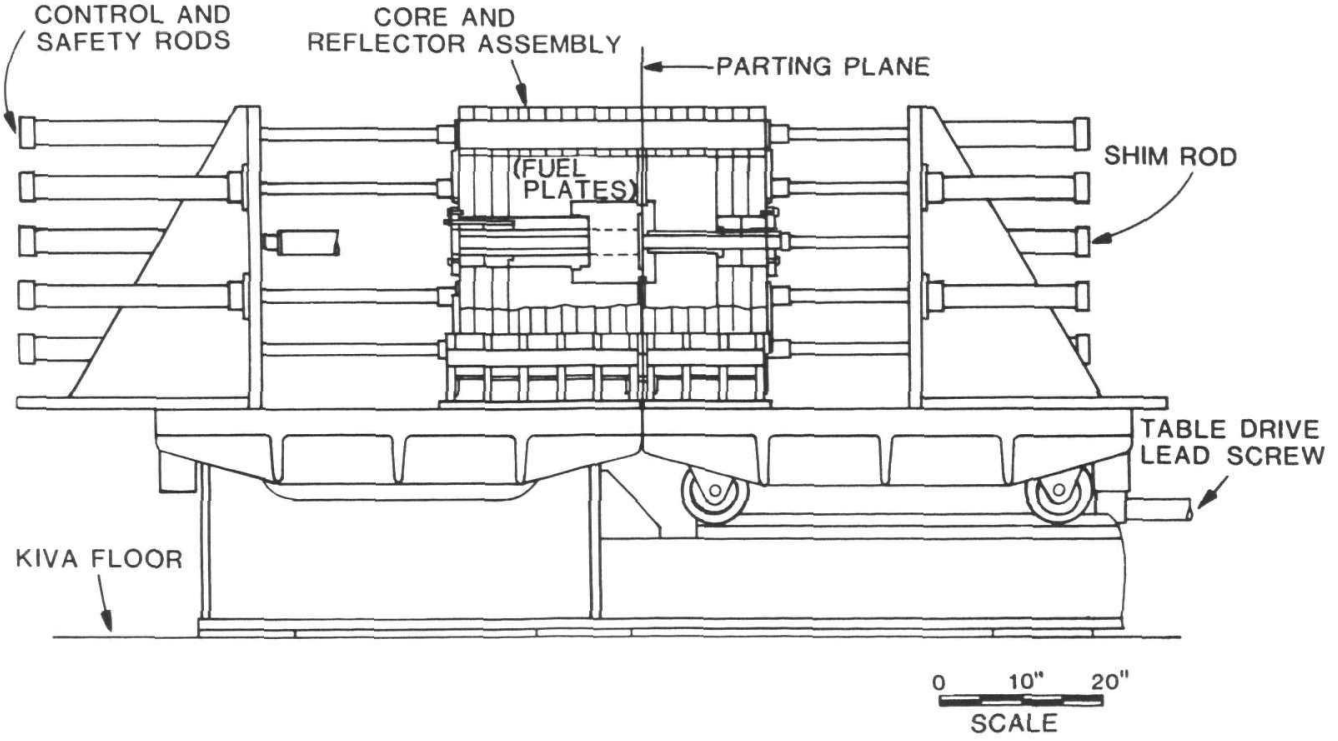

Fig. 30 .

The Big Ten critical assembly with the cart in operating position. U(10) components on the axis are surrounded by interleaved $U(93)$ and natural uranium plates averaging $U(10)$ to complete the core. The reflector is 6 -inch-thick natural uranium. 


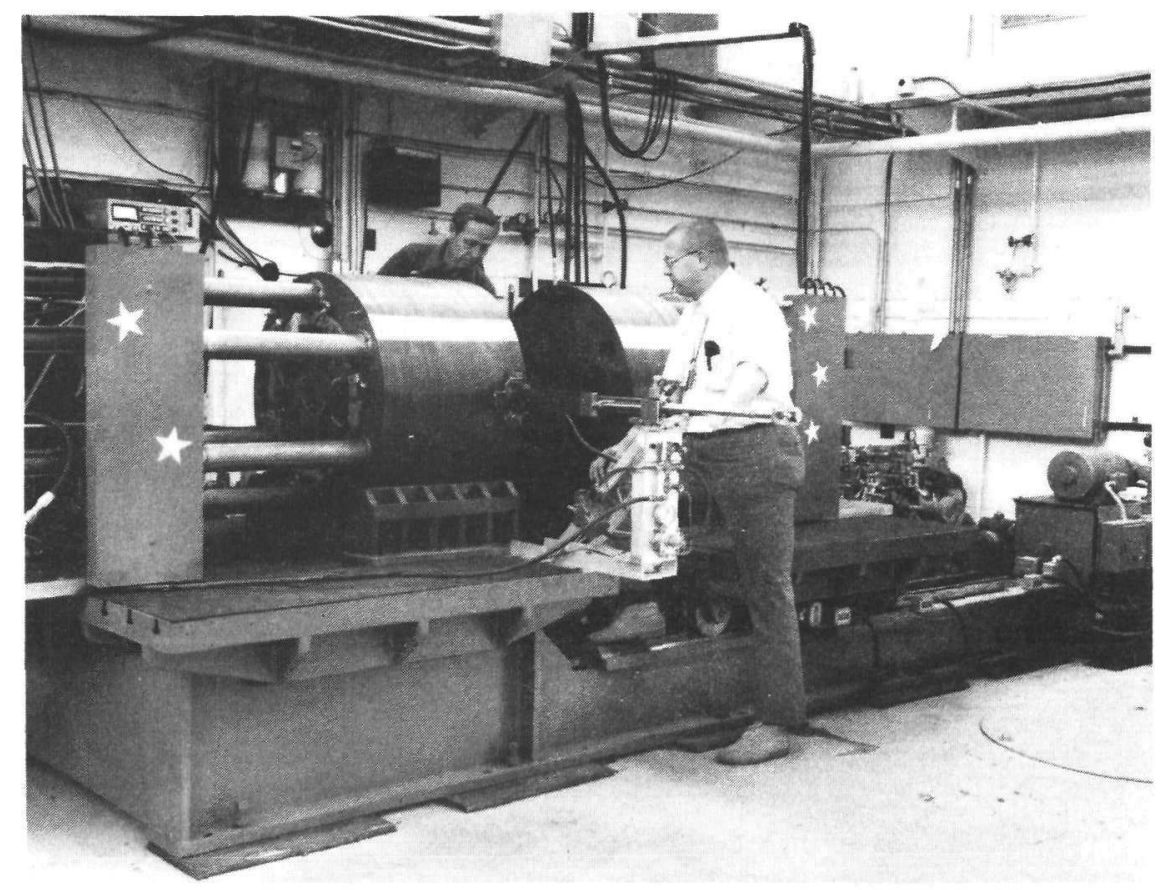

Fig. 31 .

Gordon Hansen (left) and Jerry Koelling adjust Big Ten.

assemblies that had been retained from the Rover period. The new assemblies Kinglet and Sheba were brought into operation, and the Skua fast-burst reactor was constructed.

\section{NASA-Sponsored Activities}

Active until August 1979, the major project for NASA was directed toward a plasma-core power reactor to be operated at very high temperature. In that reactor concept, a helically flowing buffer gas protected the containing vessel from the hot gaseous core. Beryllium reflector components and control drums left over from the Rover Program were essential parts of a progressive series of mockups of this reactor. In the earlier versions of this so-called Plasma Core Assembly, the gas cores were simulated by thin foils of enriched uranium, either distributed within a large cavity or lining it. In later versions, distributed Rover fuel elements were used instead of foil; then some of these elements were replaced by gaseous $\mathrm{UF}_{6}$. Although planned, a complete $\mathrm{UF}_{6}$ core was not attained.

Another NASA project was a study of gaseous lasers for transmitting power. This was related to the reactor development of a possible means of extracting power through radiation from the plasma core. A noteworthy result of this project was one of the first demonstrations of a laser pumped by uranium fission products, with Godiva IV as the neutron source (Fig. 32). Initial success was obtained with a helium-xenon laser in which the tube was lined with enriched uranium foil. 62 A polyethylene sleeve about the tube thermalized neutrons, and fission fragments excited the laser. Later, a 


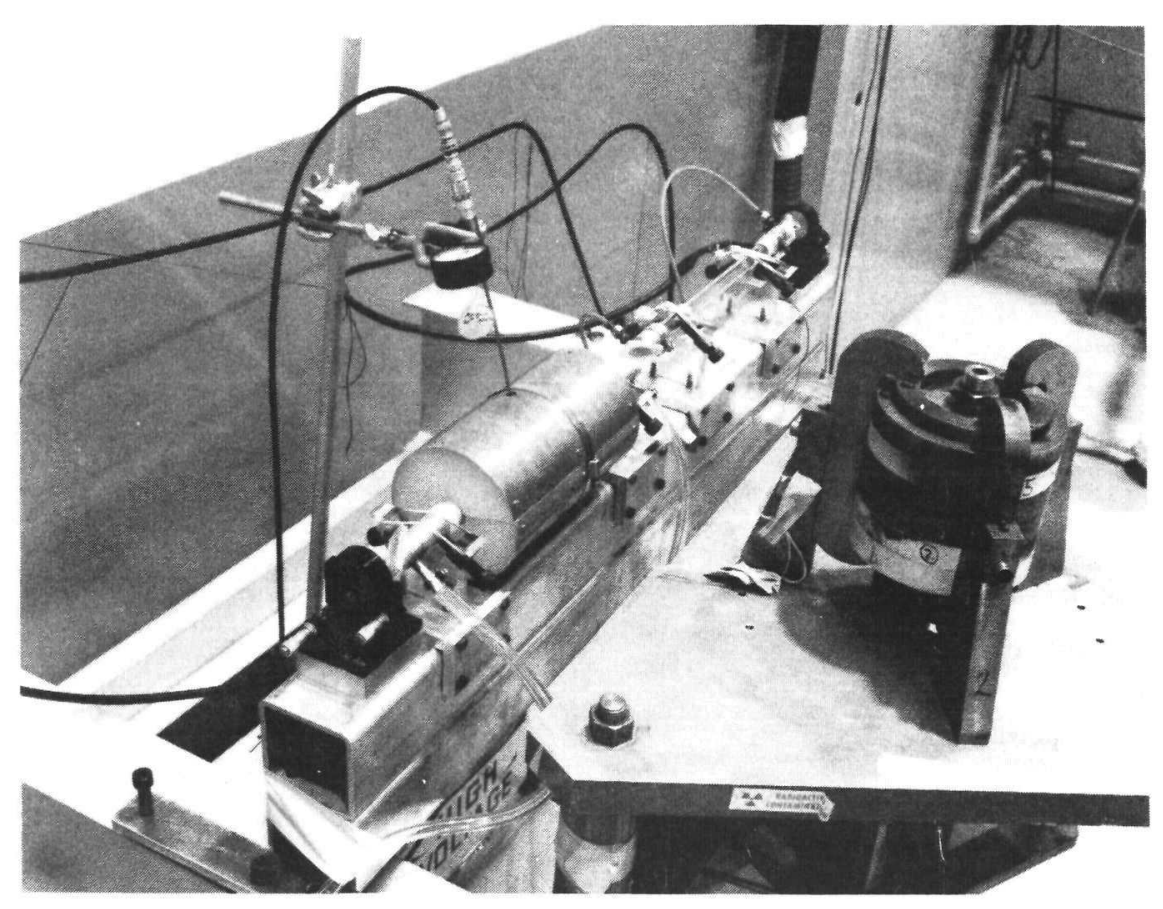

Fig. 32.

Laser for demonstration of fission-fragment pumping, with Godiva IV as the source.

similar thermalizing sleeve surrounded a ${ }^{3} \mathrm{He}-\mathrm{Xe}$ laser without foil liner. 63 Products of the reaction ${ }^{3} \mathrm{He}(n, p)^{3} \mathrm{H}$ excited this laser.

Another NASA-sponsored experiment with Godiva IV as a neutron source used a naval cannon (Fig. 33) as a chamber for compressing $\mathrm{UF}_{6}$ gas to $450 \mathrm{~atm}$ and a temperature of $1250 \mathrm{~K}$. The purpose was to investigate radiation from a uranium plasma, which was simulated by the hot gas.

\section{$\underline{\text { Parka }}$}

Following the Rover Program, Parka (the Kiwi-B4-type reactor in Kiva 3) was retained, primarily because the core readily accommodated special experiments. As examples, fast-reactor fuel was inserted to investigate diagnostic techniques, 64,65 and a $10-\mathrm{kg}$ sample of damp mixed oxide $\left(60 \% \mathrm{PuO}_{2}, 40 \%\right.$ depleted $\left.\mathrm{UO}_{2}\right)$ on the Parka axis provided information to help in the design of a proposed assembly of the material.

\section{Kinglet}

The Kinglet critical experiment (Fig. 34), conducted in 1973 and 1974, was intended to contribute to the design of the Kinetic Intense Neutron Generator, the KING reactor proposed by L.D.P. King. ${ }^{66}$ The attractive feature of the reactor was to result from a large volume of $U(93)$ solution circulating through a small critical region within a beryllium reflector. Thus, a large power density in the critical region could be maintained with a 


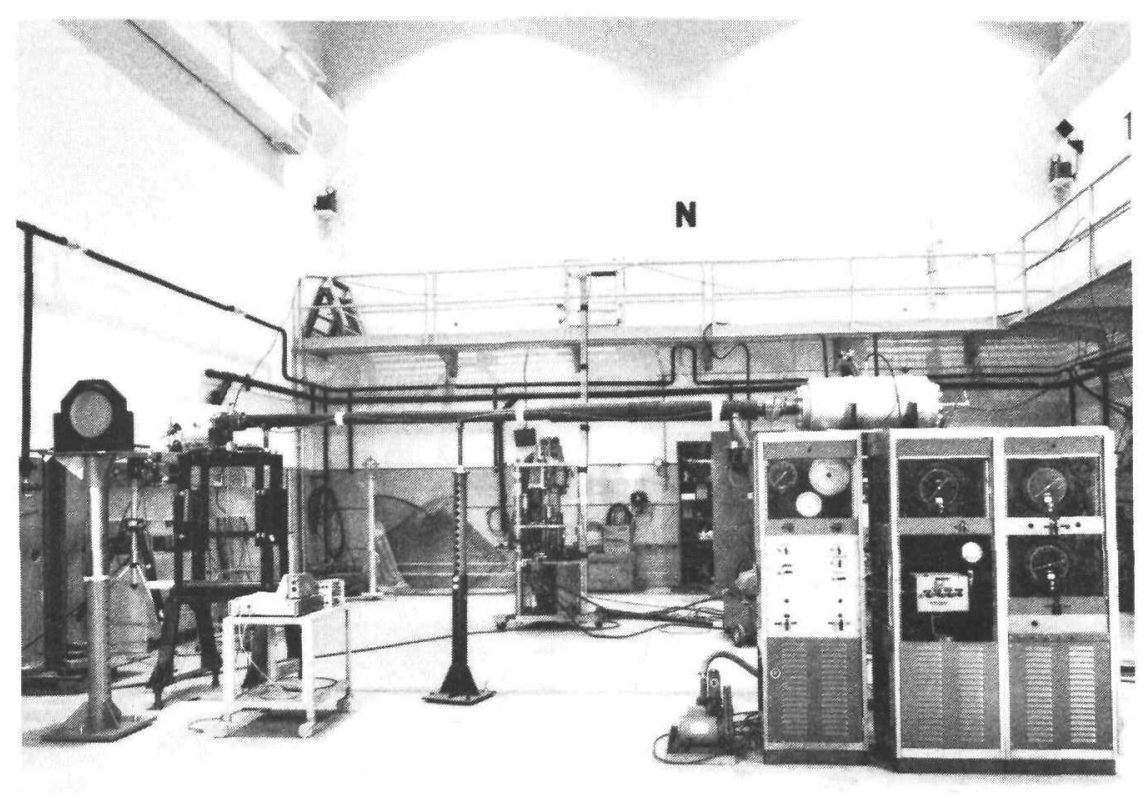

Fig. 33.

Naval cannon serving as a chamber for compressive heating of $\mathrm{UF}_{6}$ gas. Godiva IV, in the background, is a neutron source for exciting radiation from the $\mathrm{UF}_{6}$.

moderate temperature rise of the entire solution. However, conditions for stable operation were in doubt because nearly all delayed-neutron precursors would decay outside the critical volume.

The Kinglet experiment was to explore stability and the effect of radiolysis, the shutdown mechanism in the virtual absence of delayed neutrons. Kinglet, with 561 liters of solution circulating through an 8-liter critical volume, was operated for brief periods at power up to 2 MW. Power followed excess reactivity satisfactorily (oscillations above 0.2 dollar excess reactivity were attributed to vibration of unconstrained piping). The radiolytic gas contribution to reactivity quench coefficient (ratio of reactivity change to core temperature rise) proved to be proportional to fission power. The experiment was terminated when funding was discontinued.

\section{Sheba}

The Solution High-Energy Burst Assembly, 67 called Sheba, was designed especially for proof testing criticality accident detection systems. These detectors for initiating accident alarms had been calibrated by fast-neutron pulses from Godiva-like reactors, whereas all criticality accidents have occurred in solutions. Sheba generates relatively slow neutrons such as those emitted by critical solutions. Fueled with an aqueous solution of $\mathrm{U}(4.95) \mathrm{O}_{2} \mathrm{~F}_{2}$, Sheba is installed in a sheet-metal building outside Kiva 1 (Fig. 35) vacated by Kinglet. Criticality is attained by solution-height adjustment in a cylindrical vessel whose inside diameter measures $54.6 \mathrm{~cm}$. 


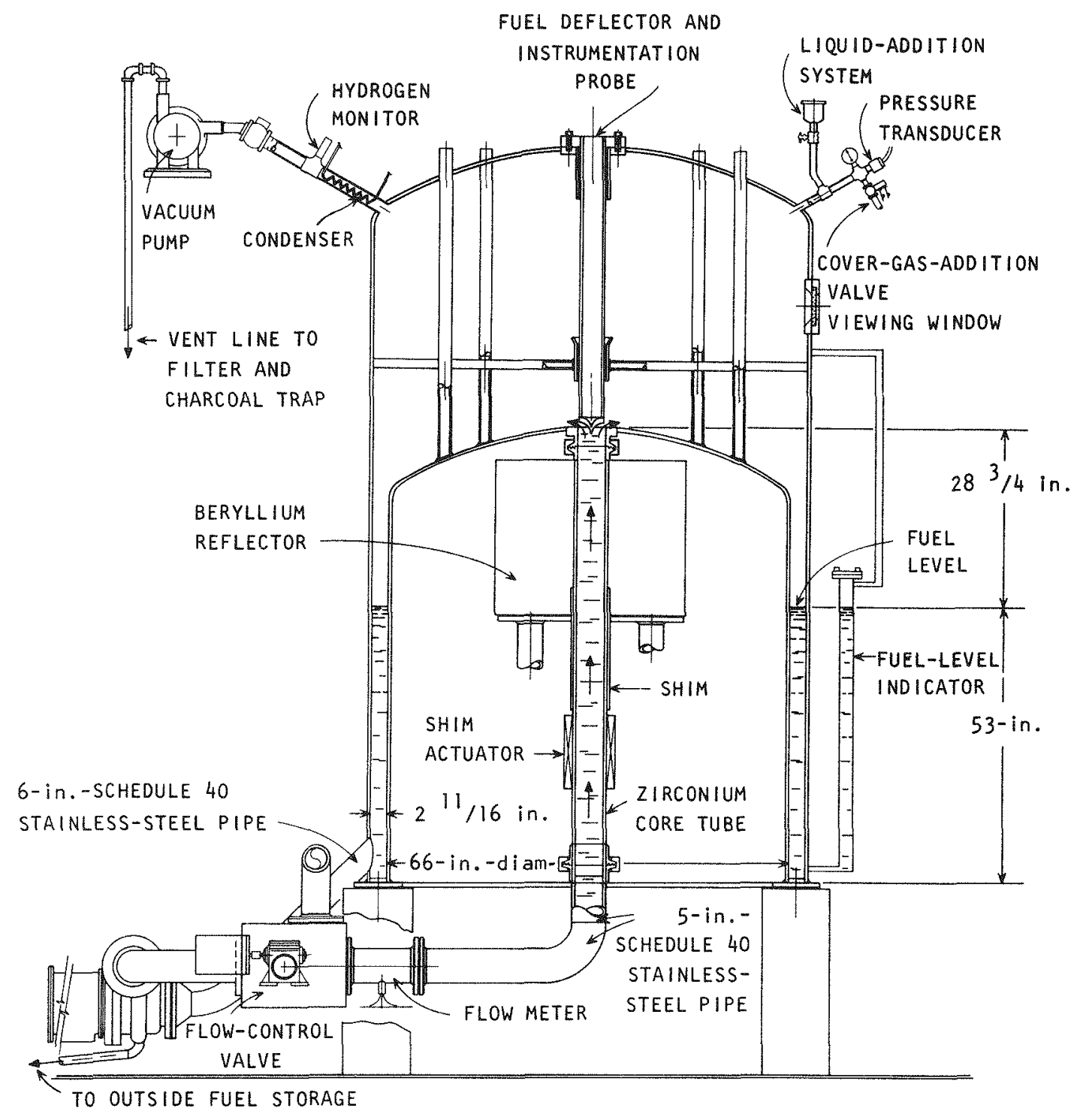

Fig. 34.

Kinglet, a flowing U(93) solution critical assembly. The critical solution within the beryllium reflector is a small fraction of the total available volume. Kinglet was set up in a sheet-metal shed outside Kiva 1.

Shutdown, by means of rapid draining into storage cylinders, is supplemented by a safety rod that can drop into a $6.35-\mathrm{cm}$-diameter axial tube. With solution at a density of $1.04 \mathrm{~kg}$ of uranium/liter (hydrogen/235 $\mathrm{U}=525$ ), criticality at $25^{\circ} \mathrm{C}$ is attained at a depth of $36.5 \mathrm{~cm}$ or a volume of 84.3 liters.

A principal use of Sheba has been in the calibration of criticality accident dosimeters for a uranium enrichment plant. It has also served as a source for skyshine measurements. The early plan for use of Sheba as a burst assembly did not materialize except to simulate very long-period excursions. 


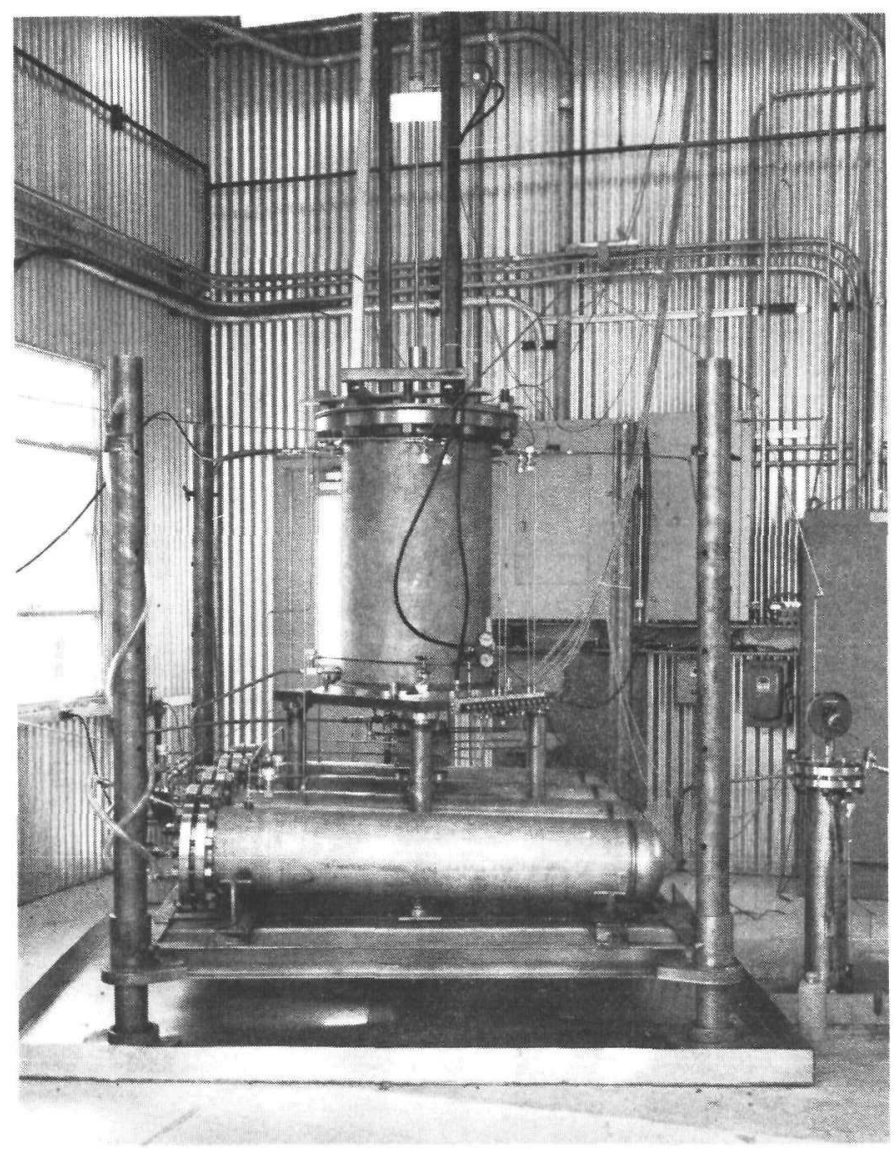

Fig. 35.

Sheba, the U(5) solution critical assembly in a sheet-metal shed outside Kiva 1 . Criticality is attained in the cylindrical vessel standing above four storage cylinders of smaller diameter.

The Supercritical Uranium Assembly, 68 called Skua, is an oversize fast-burst assembly that is not yet operating (Fig. 36). In addition to size, it differs from Godiva IV in that a copper reflector surrounds the active material, a stack of U(93)-alloy rings. Three sections of the reflector are retractable as safety blocks and three other portions rotate into the main body as control drums (Fig. 37).

Objects to be irradiated with fast neutrons may be accommodated in a 9.5-inch-diameter cavity within the alloy rings. For slow-neutron irradiations, however, a moderating insert (containing polyethylene or zirconium hydride) leaves only a 3-inch-diameter sample cavity. With the moderator in place, it is expected that pulses several times as great as in Godiva IV can be attained without damage to the alloy rings. 


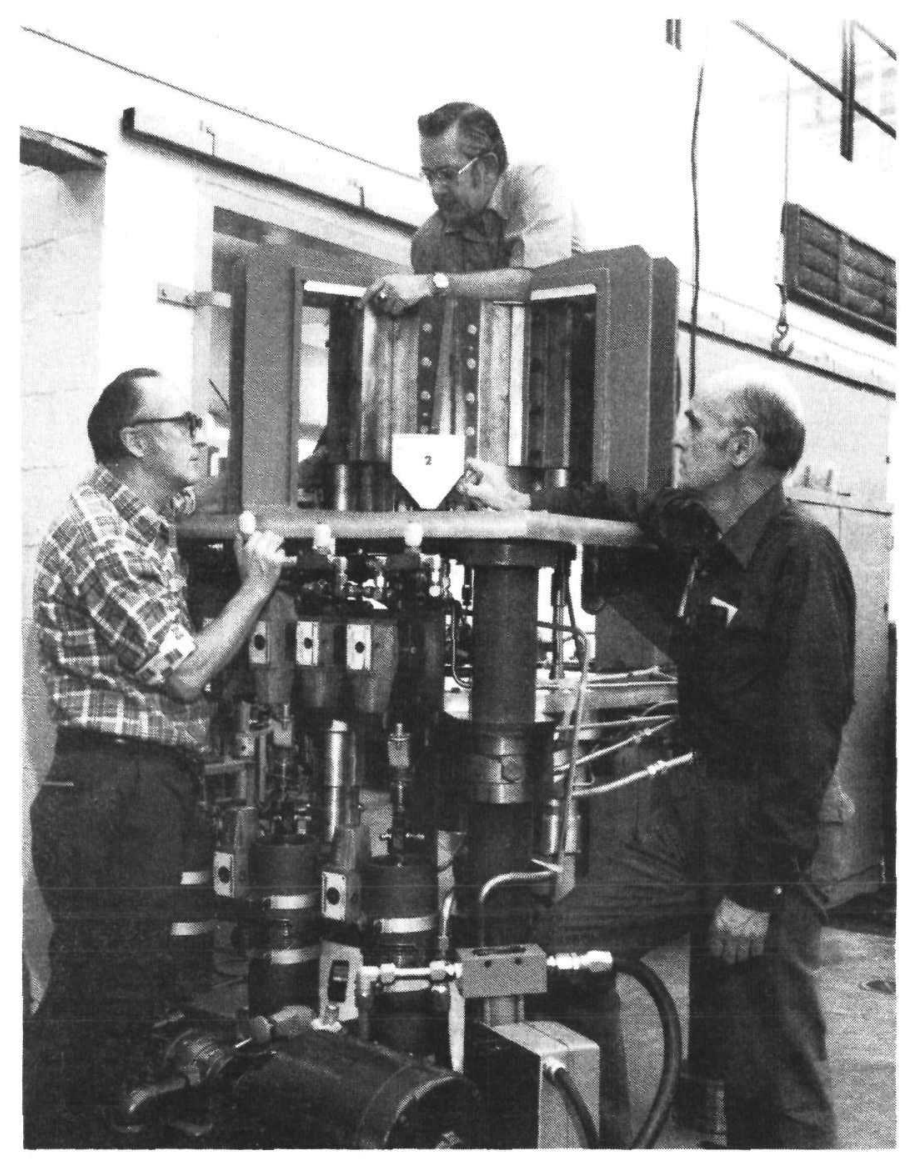

Fig. 36.

The Skua fast-burst assembly for energy deposition in axial samples. Calvin Davis (left), Edward Ferdinand (top), and Thomas Wimett are working on the copper control drums.

\section{CONTINUING CAPABILITY}

The Critical Experiments Facility at Pajarito Site is uniquely comprehensive, as illustrated by the range of critical and subcritical experiments described previously. Although metal systems most appropriate for the weapons program predominated at first, solutions and nonhydrogenous moderators were introduced as called for by reactor programs and for special studies such as effects of softened neutron spectra on detector calibration. All three fissile isotopes have been represented as solids. Solutions of ${ }^{233} \mathrm{U}$ and ${ }^{239} \mathrm{Pu}$ have not been required but are not ruled out by any limitation of the facility.

Safety tests were augmented by assemblies that became benchmarks for verifying or improving cross-section sets: Lady Godiva; Jezebel-239 $\mathrm{Pu}$ and $-233 \mathrm{U}$; Flattop- $235 \mathrm{U},-233 \mathrm{U}$, and $-239 \mathrm{Pu}$; Big Ten; and Thor. ${ }^{26}$ If desired, the very-fast-neutron pulses of Godiva IV may be supplemented by lessenergetic Skua pulses applicable to larger internal samples and by still-softer pulses from Sheba. Applications of fast-pulse assemblies included biological 

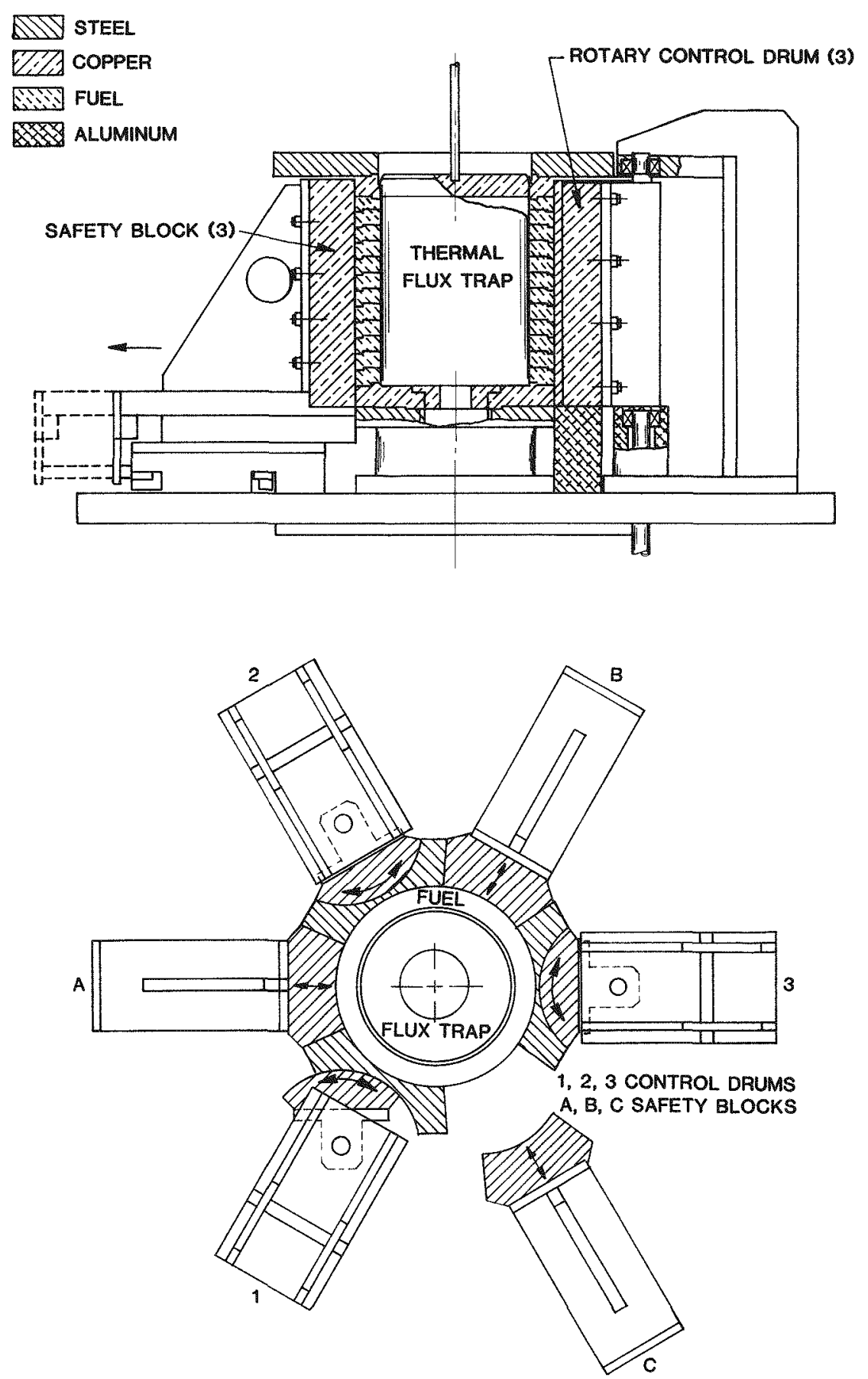

Fig. 37.

The critical portion of Skua with copper reflector, control drums, and safety block surrounding $U(93)$ alloy fuel rings. One of three safety blocks is retracted, and one control drum is rotated away from its position of greatest reactivity. 
effects, solid-state studies, proof tests of weapon diagnostic instrumentation, stimulation of nuclear-pumped lasers, and calibration of criticality accident detectors.

As more transplutonic elements become available, small samples can give effective cross sections, and larger quantities can give critical masses, which are notoriously difficult to calculate for the threshold fissioners. 69 Other experiments can be designed to resolve serious discrepancies between calculation and existing experimental data, such as exist for air-spaced arrays of enriched uranium solution and beryllium-reflected plutonium metal. These illustrate gaps in experimental data that are of most immediate concern. Other gaps may assume importance as new chemical and metallurgical processes are developed or reactor fuel combinations such as ${ }^{233} \mathrm{U}$-Th are emphasized.

\section{ACKNOWLEDGMENTS}

The work reported here was supported by the DOE and its predecessors. Special thanks are due Raemer Schreiber-for preparing the account of early days at Pajarito Site, Mac Forehand--for encouraging me to write this history, and Richard Malenfant-for enthusiastic support.

\section{REFERENCES}

1. E. C. Mallary, H. C. Paxton, and R. H. White, "Safety Tests for Storage of Fissile Units," Los Alamos Scientific Laboratory report LA-1875 (February 1955).

2. R. H. White, "Topsy, A Remotely Controlled Critical Assembly Machine," Nucl. Sci. Eng. 1, 53-61 (March 1956).

3. H. C. Paxton, "Fast Critical Experiments," in Progress in Nuclear Energy, Series IV, C. M. Nicholls, Editor (Pergamon Press Limited, Oxford, England, 1981), Vol. 7, pp. 151-174.

4. G. A. Linenberger and L. L. Lowry, "Neutron Traverses in the Topsy and Godiva Critical Assemblies," Los Alamos Scientific Laboratory report LA-1 653 (June 1953).

5. J. D. Orndoff and C. W. Johnstone, "Time Scale Measurements by the Rossi Method," Los Alamos Scientific Laboratory report LA-744 (November 1949).

6. L. B. Engle, G. E. Hansen, and H. C. Paxton, "Reactivity Contributions of Various Materials in Topsy, Godiva, and Jezebel," Nucl. Sci. Eng. 543-569 (December 1960).

7. G. E. Hansen, J. D. Orndoff, and H. C. Paxton, "Critical Masses of Oralloy at Reduced Concentrations and Densities," Los Alamos Scientific Laboratory report LA-1251 (May 1951). 
8. H. C. Paxton and G. A. Linenberger, "Polyethylene-25 Critical Assembly and Neutron Distribution Studies," Los Alamos Scientific Laboratory report LA-749 (May 1950).

9. H. C. Paxton, J. D. Orndoff, and G. A. Linenberger, "Oy Hydride Critical Assemblies," Los Alamos Scientific Laboratory report LA-1159 (May 1950).

10. G. A. Jarvis, G. A. Linenberger, J. D. Orndoff, and H. C. Paxton, "Two Plutonium-Metal Critical Assemblies," Nucl. Sc1. Eng. $\underline{8}$, 525-531 (December 1960).

11. D. S. Young, "Neutron Distribution Measurements at Pajarito by Means of Photographic Emulsions," Los Alamos Scientific Laboratory report LA-1487 (May 1952).

12. J. D. Orndoff and H. C. Paxton, "Measurements on Untamped Oralloy Assembly," Los Alamos Scientific Laboratory report LA-1209 (February 1951).

13. R. E. Peterson and G. A. Newby, "An Unreflected U-235 Critical Assembly," Nuel. Sci. Eng. 1, 112-125 (May 1956).

14. T. F. Wimett, L. B. Engle, G. A. Graves, G. R. Keepin, and J. D. Orndoff, "Time Behavior of Godiva Through Prompt Critical," Los Alamos Scientific Laboratory report LA-2029 (April 1956).

15. G. E. Hansen, "Burst Characteristics Associated with the Slow Assembly of Fissionable Materials," Los Alamos Scientific Laboratory report LA-1441 (July 1952).

16. H. C. Paxton, "Thirty-Five Years at Pajarito Canyon Site," Los Alamos National Laboratory report LA-7121-H(Rev.) (May 1981).

17. H. C. Paxton, "Safety Analysis of the Los Alamos Critical Experiments Facility," Los Alamos Scientific Laboratory report LA-6206, Vol. I, pp. 17-18 (February 1976).

18. T. F. Wimett, R. H. White, W. R. Stratton, and D. P. Wood, "Godiva II An Unmoderated Pulse-Irradiation Reactor," Nucl. Sci. Eng. 8, 691-708 (December 1980).

19. R. N. Olcott, "Homogeneous Heavy Water Moderated Critical Assemblies," Nucl. Sci. Eng. 1, 327-341 (August 1956).

20. H. C. Paxton, G. A. Linenberger, L. L. Lowry, R. N. Oleott, and J. D. Orndoff, "Bare Critical Assemblies of Oralloy at Intermediate Concentrations of U-235," Los Alamos Scientific Laboratory report LA-1671 (May 1954).

21. J. J. Neuer, "Critical Assembly of Uranium Metal at an Average Concentration of $16-1 / 4 \%, "$ Los Alamos Scientific Laboratory report LA-2085 (January 1957). 
22. E. C. Mallary, G. E. Hansen, G. A. Linenberger, and D. P. Wood, "Neutron Burst from a Cylindrical Untamped Oy Assembly," Los Alamos Scientific Laboratory report LA-1477 (July 1952).

23. H. C. Paxton, "Critical Assembly Booby Traps," Nucleonics 16, 80-81 (March 1958).

24. W. R. Stratton, "A Review of Criticality Accidents," Los Alamos Scientific Laboratory report LA-3611 (January 1967).

25. G. E. Hansen and H. C. Paxton, "Reevaluated Critical Specifications of Some Los Alamos Fast-Neutron Systems," Los Alamos Scientific Laboratory report LA-4208 (September 1969).

26. R. B. Kidman, "Los Alamos Benchmarks: Calculations Based on ENDF/B-V Data," Los Alamos National Laboratory report LA-9037-MS (November 1981).

27. W. F. Stubbins, D. M. Barton, and F. D. Lonadier, "The Neutron Production Cross Section of ${ }^{238} \mathrm{Pu}$ in a Fast Spectrum," Nucl. Sci. Eng. 25, 377-382 (August 1966).

28. D. M. Barton, "Central Reactivity Contributions of ${ }^{244} \mathrm{Cm},{ }^{239} \mathrm{Pu}$, and $235 \mathrm{U}$ in a Bare Critical Assembly of Plutonium Metal," Nucl. Sci. Eng. 33, 51-55 (July 1968).

29. W. Bernard, "Hydro: A Small Water-Cooled and Water-Reflected Neutron Source," Los Alamos Scientific Laboratory report LA-3374 (March 1966).

30. J. J. Neuer, C. B. Stewart, G. A. Jarvis, R. N. Olcott, D. S. Young, and J. E. Sattizahn, "Preliminary Survey of Uranium Metal Exponential Columns," Los Alamos Scientific Laboratory report LA-2023 (January 1956).

31. C. G. Chezem, "A Uranium-Metal Exponential Experiment," Nucl. Sci. Eng. 8, 652-669 (December 1960).

32. C. G. Chezem and E. J. Lozito, "Investigation of the Criticality of Low-Enrichment Uranium Cylinders," Nucl. Sci. Eng. 33, 139 (July 1968).

33. F. F. Hart, "Safety Tests for Melting and Casting Oralloy," Los Alamos Scientific Laboratory report LA-1623 (December 1953).

34. H. C. Barkmann, B. M. Carmichael, D. M. Holm, R. M. Kiehn, R.E. Peterson, D. E. Schwarmer, J. W. Woolsey, J. Grundl, R. G. Wagner, T. F. Wimett, and R. H. White, "Preliminary Critical Experiments on a Mockup of the Los Alamos Molten Plutonium Reactor," Los Alamos Scientific Laboratory report LA-2 142 (June 1957).

35. R. W. Spence, "The Rover Nuclear Rocket Program," Science 160, 953-959 (May 1968). 
36. G. E. Hansen, J. C. Hoogterp, J. D. Orndoff, H. C. Paxton, W. H. Roach, and D. P. Wood, "Beryllium-Reflected Graphite-Moderated Critical Assemblies," Los Alamos Scientific Laboratory report LA-2141 (July 1957).

37. J. D. Orndoff, J. C. Hoogterp, D. M. Barton, C. C. Byers, and D. P. Wood, "Nuclear Propulsion Test Reactor Kiwi-A Neutronic Studies," Los Alamos Scientific Laboratory report LA-2284 (September 1958).

38. C. G. Chezem, G. E. Hansen, H. H. Helmick, and R. L. Seale, "The Los Alamos Coupled Reactor Experience," Los Alamos Scientific Laboratory report LA-3494 (January 1967).

39. R. E. Malenfant, "Two Novel Radiation Calculations on Rocket Reactors," Proc. Nucl. Propulsion Conf., Monterey, California, August 15-17, 1962 (U.S. AEC report TID-7653, Pt. II, Book 1, 1962), pp. 99-103.

40. D. A. MeCutchan, "Transport Calculation of the Kiwi-B Neutron Environment," Proc. Nucl. Propulsion Conf., Monterey, California, August 15-17, 1962 (U.S. AEC report TID-7653, Pt. II, Book 1, 1962), pp. 104-108.

41. J. R. Streetman and G. A. Graves, "Monte Carlo Calculation of Neutron Heating in a Nuclear Rocket Propellant Tank," Los Alamos Scientific Laboratory report LA-2909 (Apri1 1963).

42. R. E. Malenfant, "QAD: A Series of Point-Kernel General-Purpose Shielding Programs," Los Alamos Scientific Laboratory report LA-3573 (April 1967).

43. J. R. Streetman, "Program and QAD V for Calculation of Volume Heating," Los Alamos Scientific Laboratory report LA-3573 (Supplement) (April 1968).

44. C. W. Watson, "Monte Carlo Calculations of Gamma-Ray Heating Rates and Fluxes in Phoebus 1 from Core Sources," Los Alamos Scientific Laboratory report LA-3577 (December 1966, Supplement October 1969).

45. C. W. Watson, G. A. Graves, and J. R. Streetman, "Neutron Monte Carlo Calculations for a 1000-MW Propulsion Reactor," Los Alamos Seientific Laboratory report LA-3635 (August 1967).

46. C. W. Watson, "Fissioning Neutron Fluence Distributions in the Phoebus 1B Facility Shield," Los Alamos Scientific Laboratory report LA-4166 (October 1969).

47. J. L. Sapir, "Twenty-Five Group Cross Sections Used in the Los Alamos Rover Program," Los Alamos Scientific Laboratory report LA-4484-MS (August 1970).

48. C. W. Watson, "Measured ${ }^{235} \mathrm{U}$ and $238 \mathrm{U}$ Fissioning Neutron Fluence Distributions in the Phoebus 2A Shields: Comparison with Monte Carlo Calculations," Los Alamos Scientific Laboratory report LA-4615 (March 1971). 
49. D. M. Barton, H. H. Helmick, and G. A. Jarvis, "Instrumentation and Some Related Problems for Neutron Flux Measurements of the Los Alamos Scientific Laboratory Kiwi-A Reactor," Los Alamos Scientific Laboratory report LAMS-2258 (September 1958).

50. S. J. Balestrini, C. C. Byers, A. M. Gage, and J. D. Orndoff, "Critical Assembly Mockup Studies of the Phoebus 2 Rover Reactor," Los Alamos Scientific Laboratory report LA-3580-MS (November 1966).

51. E. A. Plassmann, "Neutronic Calculations of Temperature Effects on Kiwi Reactors," Proc. Nucl. Propulsion Conf., Monterey, California, August 15-17, 1962 (U.S. AEC report TID-7653, Pt. II, Book 1, 1962), pp. 49-55.

52. J. C. Hedstrom, W. K. Kirk, and J. L. Sapir, "Phoebus 2A Reactivity Analysis," Los Alamos Scientific Laboratory report LA-4180-MS (June 1969).

53. H. C. Paxton, G. A. Jarvis, and C. C. Byers, "Reflector-Moderated Critical Assemblies," Los Alamos Scientific Laboratory report LA-5963 (July 1975).

54. W. Bernard, H. H. Helmick, G. A. Jarvis, E. A. Plassmann, and R. H. White, "Research Program on Plasma Core Assembly," Los Alamos Scientific Laboratory report LA-5971-MS (May 1975).

55. J. F. Jaminet and J. S. Kendall, "Vortex-Confined Uranium Hexafloride Cavity Reactor Experiments," United Technologies Research Center report $\mathrm{R} 80-914499-4$ (April 1980).

56. G. E. Hansen and H. C. Paxton, "Thor, A Thorium-Reflected PlutoniumMetal Critical Assembly," Nucl. Sci. Eng. 71, 287-293 (September 1979).

57. J. A. Auxier, J. S. Cheka, H. H. Hubbel, Jr., D. R. Johnson, T. D. Jones, P. T. Perdue, and J. H. Thorngate, "Ichiban Studies," Oak Ridge National Laboratory report OR NL-3849, pp. 153-159 (July 1965).

58. G. A. Jarvis and C. B. Mills, "Critical Mass Reduction," Los Alamos Scientific Laboratory report LA-3651 (March 1967).

59. D. M. Barton, W. Bernard, and G. E. Hansen, "Critical Masses of Composites of $\mathrm{Oy}$ and Pu-239-240 in Flattop Geometry," Los Alamos Scientific Laboratory report LAMS-2489 (December 1960).

60. T. F. Wimett, R. H. White, and R. G. Wagner, "Godiva IV," Proc. ANS National Topical Meeting, Fast Burst Reactors, University of New Mexico, Albuquerque, New Mexico, January 28-30, 1969 (AEC 15 Symposium Series), pp. 95-104.

61. G. E. Hansen and H. C. Paxton, "A Critical Assembly of Uranium Enriched to $10 \%$ in Uranium-235," Nucl. Sei. Eng. 72, 230-236 (November 1979). 
62. H. H. Helmick, J. L. Fuller, and R. T. Schneider, "Direct Nuclear Pumping of a Helium-Xenon Laser," Appl. Phys. Lett. 26, 327-328 (March 1975).

63. C. R. Mansfield, P. F. Bird, J. F. Davis, T. F. Wimett, and H. H. Helmick, "Direct Nuclear Pumping of a ${ }^{3} \mathrm{He}-\mathrm{Xe}$ Laser," Appl. Phys. Lett. 30, 640-641 (June 1977).

64. A. E. Evans, Jr., J. D. Orndoff, and W. L. Talbert, Jr., "Evaluation of LMFBR Fuel-Motion Diagnostics with PARKA," IEEE Trans. Nucl. Sci. N-26, No. 1 (February 1979), pp. 815-823.

65. C. L. Fink, A. DeVolpi, E. A. Rhodes, and A. E. Evans, "Analysis of the 91-Pin Subassembly Tests at PARKA," IEEE Trans. Nucl. Sci. N-26, No. 1 (February 1979), pp. 827-830.

66. T. F. Wimett and H. C. Paxton, "KINGLET Critical Assembly: An Experiment with Flowing Fissile Solution," Nucl. Sci. Eng. 78, 425-431 (August 1981).

67. R. E. Malenfant and H. M. Forehand, Jr., "Facility Description of a Solution Critical Assembly: SHEBA," ANS Trans. 39, 555-557 (December 1981).

68. J. D. Orndoff, H. C. Paxton, and T. F. Wimett, "Safety Analysis of the Los Alamos Critical Experiments Facility: Burst Operation of Skua," Los Alamos Scientific Laboratory report LA-6206, Vol. II Addendum (Rev. 1) (December 1980).

69. R. M. Westfall, "Critical Masses for the Even-Neutron-Numbered Transuranic Actinides," Nucl. Sci. Eng. 79, 237-239 (October 1981). 